\title{
Design Low Order Robust Controller for the Generator's Rotor Angle Stabilization PSS System
}

\author{
Vu Ngoc Kien ${ }^{1}$, Nguyen Hien Trung ${ }^{1}$, Nguyen Hong Quang ${ }^{1 *}$ \\ ${ }^{1}$ Thai Nguyen University of Technology, 666,3/2 Street, Tich Luong Ward, Thai Nguyen City 251750, Viet Nam
}

\begin{abstract}
The electrical system's problem stabilizes the electrical system with three primary parameters rotor angle stability, frequency stability, and voltage stability. This paper focuses on the problem of designing a low-order stable optimal controller for the generator rotor angle (load angle) stabilization system with minor disturbances. These minor disturbances are caused by lack of damping torque, change in load, or change in a generator during operation. Using the $\mathrm{RH}_{\infty}$ optimal robust design method for the Power System Stabilizer (PSS) to stabilize the generator's load angle will help the PSS system work sustainably under disturbance. However, this technique's disadvantage is that the controller often has a high order, causing many difficulties in practical application. To overcome this disadvantage, we propose to reduce the order of the higher-order optimal robust controller. There are two solutions to reduce order for high-order optimal robust controller: optimal order reduction according to the given controller structure and order reduction according to model order reduction algorithms. This study selects the order reduction of the controller according to the model order reduction algorithms. In order to choose the most suitable low-order optimal robust controller that can replace the high-order optimal robust controller, we have compared and evaluated the order-reducing controllers according to many model order reduction algorithms. Using robust low-order controllers to control the generator's rotor angle completely meets the stabilization requirements. The research results of the paper show the correctness of the controller order reduction solution according to the model order reduction algorithms and open the possibility of application in practice.
\end{abstract}

\section{Keywords:}

Electrical System Stabilization; Generator's Rotor Angle;

Power System Stabilizer;

$\mathrm{RH}_{\infty}$ Robust Optimal Controllers; Order Reduction Algorithm.

Article History:

$\begin{array}{llll}\text { Received: } & 10 & \text { June } & 2021 \\ \text { Revised: } & 19 & \text { August } & 2021 \\ \text { Accepted: } & 02 & \text { September } & 2021 \\ \text { Published: } & 01 & \text { October } & 2021\end{array}$

\section{1- Introduction}

The function of an electrical system is to convert energy from a natural form to an electrical form and transmit it to consumption. Easy to transmit and control with high efficiency and reliability is the convenience of electrical energy. During the power system operation, it is necessary to maintain the balance between power consumption and generating power (generator's rotor angle), ensuring power quality such as constant system frequency, constant node voltage, etc. Control purposes are based on the operating mode of the electrical system. Under normal conditions, the sense of control ensures that the voltage and frequency are close to the rated value. When abnormal conditions arise, the controller aims to return the system to normal mode. It is called system stabilization. Therefore, controlling the electrical system means stabilizing the electrical system with three primary parameters: generator's rotor angle stability, frequency stability, and voltage stability. In this paper, we focus on the problem of generator's rotor angle stabilization. Specifically, we consider a problem as follows: when there is a required load to a station with many units, the power distribution unit (AGC Automatic Generation Control) will be in charge of assigning power to the units to obtain a balance. However, since the dynamics of each generator are different, power flows are exchanged within the generator station or between the

* CONTACT: quang.nguyenhong@tnut.edu.vn

DOI: http://dx.doi.org/10.28991/esj-2021-01299

(C) 2021 by the authors. Licensee ESJ, Italy. This is an open access article under the terms and conditions of the Creative Commons Attribution (CC-BY) license (https://creativecommons.org/licenses/by/4.0/). 
generator station and the system over the transmission lines. These coupling effects cause the generator's rotor to oscillate around the working point. Another source of rotor angle oscillation is the use of a fast-response exciter. An Automatic Voltage Regulator (AVR) improves the limit of static and dynamic stability but reduces the damping torque component, detrimental to small signal stability [1]. The effects of oscillation are as follows: when the fluctuation of the rotor angle makes the rotor speed no longer the synchronous speed, the rotor angle may exceed 90 degrees of electrical current, causing the generator operation to be out of sync. In the case of not being controlled in time, it is most likely to resonate with other oscillations causing severe out of sync between the generators and the grid, even causing a disintegration of the electrical system.

In the classification of electrical system stability [2, 3], rotor angle stabilization $(\delta)$ is divided into two categories: small signal stability (minor disturbances) and transient stabilization (significant disturbances). In this paper, we only consider the problem of small signal stability (minor disturbances). These disturbances are considered small enough to use the system's linear equations for stability analysis. Small signal stabilization theory has used to identify and analyses electric motor oscillations (low-frequency oscillations) in electrical systems. These oscillations cause the generator rotor angle to increase or decrease relative to the working point, causing a lack of synchronous torque or damping torque [4]. Low-frequency oscillations include the following forms [5, 6]:

Local Mode Oscillations: These oscillations usually involve one or more generators rotating synchronously together at a power plant versus an extensive power system or load center. The frequency ranges from $0.7-2 \mathrm{~Hz}$. These oscillations are disturbing when the plant is at a high load with an extensive reactive power transmission system [1].

Inter-area Oscillations: These oscillations usually involve combinations of many generators on one part of a power system swinging against generators on another part of the power system. The frequency of inter-area oscillations is usually less than $0.5 \mathrm{~Hz}[1]$.

Global Oscillations: These oscillations involve many large electrical systems that are interconnected on a large scale. The oscillation frequency is less than $0.2 \mathrm{~Hz}$.

The oscillating quenching control is performed via a magnetic excitation system. In the synchronous generator, shortcircuit loops were arranged on the rotor (choke coil) to dissipate the vibrating energy and make the generator's oscillations shut down more quickly. However, it cannot eliminate all oscillations. The solution to this problem is to use a Power System Stabilizer (PSS) that operates through the Automatic Voltage Regulator (AVR). The PSS's task is to estimate the oscillation $\Delta \delta(\mathrm{t})$, send the voltage signal, $\mathrm{V}_{\mathrm{ss}}$, to the exciter circuit to create an electromagnetic moment component that quenches the oscillation. Instead of directly measuring the rotor angle $\delta$, it is common to measure the rate of change of the rotor speed $\Delta \omega(\mathrm{t})$, and/or generator electrical power, $\mathrm{P}_{\mathrm{e}(\mathrm{t})}$, isometric to $\Delta \delta(\mathrm{t})$. These two signals are used as inputs to the PSS. To improve the damping of the oscillations, the PSS must produce an electric torque component in phase with the rotor speed deviation $\Delta \omega$.

Furthermore, the PSS must have a suitable phase compensation circuit to compensate for the phase delay between the exciter input and the electromagnetic torque output. In fact, the generators interact through voltage and current, the kinetic effect of the machines is different. Therefore, particular consideration must be given when designing a PSS, known as the tuning of PSS in a multi-generator system. In general, they all focus on methods such as damping torque, frequency response, or eigenvalue and state matrix. There have been many studies on PSS, but most of them focus on selecting PSS's parameters according to the existing hard structure (IEEE standard). For example, choose the optimal parameter $\mathrm{H}_{\infty}$ for PSS [7, 8]; Apply $\mathrm{H}_{2}$ norm to select parameters for PSS [9, 10]. Besides, some authors also researched to design a PSS integrating requirements such as changing parameters or changing working conditions to obtain a similar frequency domain model through a suitable compensatory correction function. The goal of this method is to obtain the desired system response. The robust PSS design method uses analytical structure $\mu$ to select parameters for PSS [11], [12]. The open-loop transfer function between the exogenous outputs to the disturbance has been formatted with weighted filters for control. This is known as the "loop-shaping" control [13]. This optimization problem is solved by the DK interaction [14] technique in Matlab. The success of the above methods relies heavily on weights but does not provide a clear rule to apply in the future. If solving the optimal control problems has limitations, the $\mathrm{H}_{\infty}$ norm approach to solving linear matrix inequality (LMI) can be applied. The advantage of this technique is that it can be used for various control purposes, such as noises filtered by forced optimal control, $\mathrm{H}_{\infty}$, via $\mathrm{H}_{2}$, and polarization via the LMI. Also, it can be combined with the suboptimal control technique. Suboptimal control via LMI approach has been applied to the sustainable PSS design by both working state and output feedback [15-17].

Recently, the development of programmable and intelligent control techniques, such as genetic algorithms, neural networks, and fuzzy logic, etc. has solved many engineering problems. The genetic algorithm was used to design PSS to suppress rotor angle oscillation [18, 19]. The neural network technique was used to create parameter adjustment for PSS [20]. According to fuzzy theory, the PSS design method has also been applied by Hariri and Malik's work [21], or the result of Hosseinzadeh \& Kalam (1999) [22]. Particle Swarm Optimization (PSO) technique is used to design robust Power System Stabilizer (PSS) to improve the dynamic stability of the power system [23]. The optimized type-2 fuzzy 
logic controller is used for designing a power system stabilizer PSS combined with the robust $\mathrm{H}_{\infty}$ tracking control to increase the stability of the power system [24]. Using hybrid modified grey wolf optimization-sine cosine algorithm for tuning the parameters of PSS of an interconnected multimachine power system [25]. Collective Decision Optimization (CDO), Grasshopper Optimization Algorithm (GOA) and Salp Swarm Algorithm (SSA) have been applied for the optimal tuning of PSS parameters for small signal stability analysis of a renewable integrated power network [26, 27].

The above analysis shows that there are many separate arguments for PSS parameter selection with predetermined structure and the currently used PSS parameters are not the best. Also, the PSS structure in use is not optimal, and the PSS design strategy for structure optimization has not had much research. Therefore, in Trung (2012) [28], the task of designing the optimal PSS structure based on the $\mathrm{RH}_{\infty}$ theory has been set out and then tested, evaluated, and compared with the standard architecture PSS in use today. This research has obtained a robust optimal controller that helps the PSS system work sustainably with disturbances than conventional PSS. The high order controller can make the controller's calculation time longer, hence the response speed of the controller slower, reducing the practical applicability of the controller. Therefore, the problem of order reduction of high order controllers is a very concerning issue in robust control. For the order-reduced controller to be able to replace the high-order controller, it must satisfy the following conditions: (i) small order reduction error, i.e., deviation of the step response, the bode response of the order-reduced controller compared to the original controller is small; (ii) order of the reduced controller is low. The order-reduced controller still ensures the control quality equivalent to that of the high-order controller (expressed through the static quality criteria, the control system's dynamic quality criteria).

To obtain a low-order controller, we can do the following two methods, shown in Figure 1:

Method 1: This method selects a fixed structure of the order-reduced controller, then applies the optimization algorithm to find the order-reduced controller's parameters so that the standards of the robust control are still ensured.

Method 2: This method performs an order reduction of a high-order controller according to the model order reduction algorithms to obtain a low-order controller.

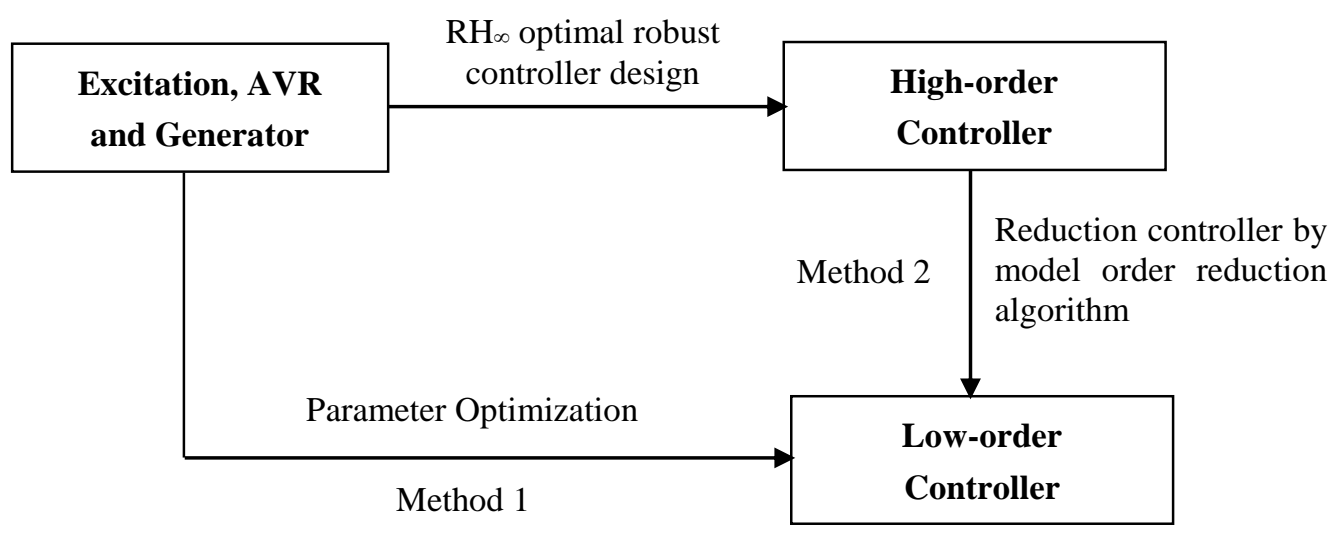

Figure 1. Two methods of designing low order robust controller for the generator's rotor angle stabilization PSS system.

To implement Method 1, we need to solve two problems simultaneously, namely, the controller design problem that satisfies the robust optimization criteria and the problem of finding controller parameters. The complexity of Method 1 is high, and the problem of finding parameters can be inexhaustible if the selected controller structure is not suitable. In contrast, Method 2 usually finds a low-order controller in all cases.

In this paper, we use the Method 2 to reduce the order of a high-order controller. The paper's objective is to compare and evaluate the effectiveness of the existing order reduction algorithms for the order reduction problem. The high-order controller that requires order reduction here is the PSS system controller that stabilizes the generator's rotor angle. After comparison and evaluation, the most robust low-order controller will be selected.

The rest of the paper is structured as follows: The mathematical model of the generator's rotor angle stabilization system is presented in Section 2. Section 3 introduces the results of the design of the generator rotor angle stabilizer controller. Section 4 presents the results of order reduction for a high-order controller and simulates a generator rotor angle control system using a low-order controller. A conclusion is drawn in Section 5.

\section{2- Mathematical Model of the Generator's Rotor Angle Stabilize System}

This study examines the principle diagram of a single generator connected to an extensive power system's busbar, as shown in Figure 2. There is no need to show the speed controller in the diagram because its response is relatively slow compared to that of the excitation system. The study aims to stabilize the small signal to suppress the oscillations, so we use a linearized model around the working point. 


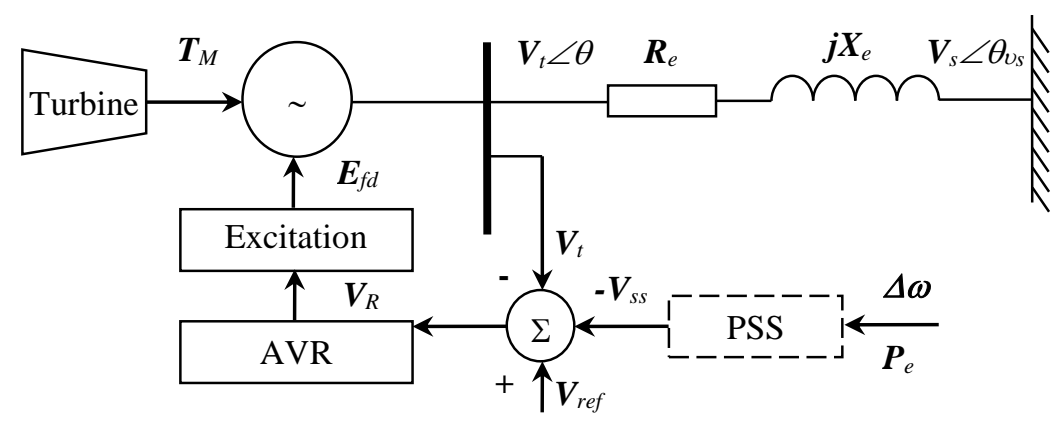

Figure 2. Block diagram of exciter controllers for grid-connected generators.

Using the ST1A typed thyristor excitation system [29], the study in Trung (2012) [28] has obtained a linear generator block diagram including exciter and AVR, as shown in Figure 3.

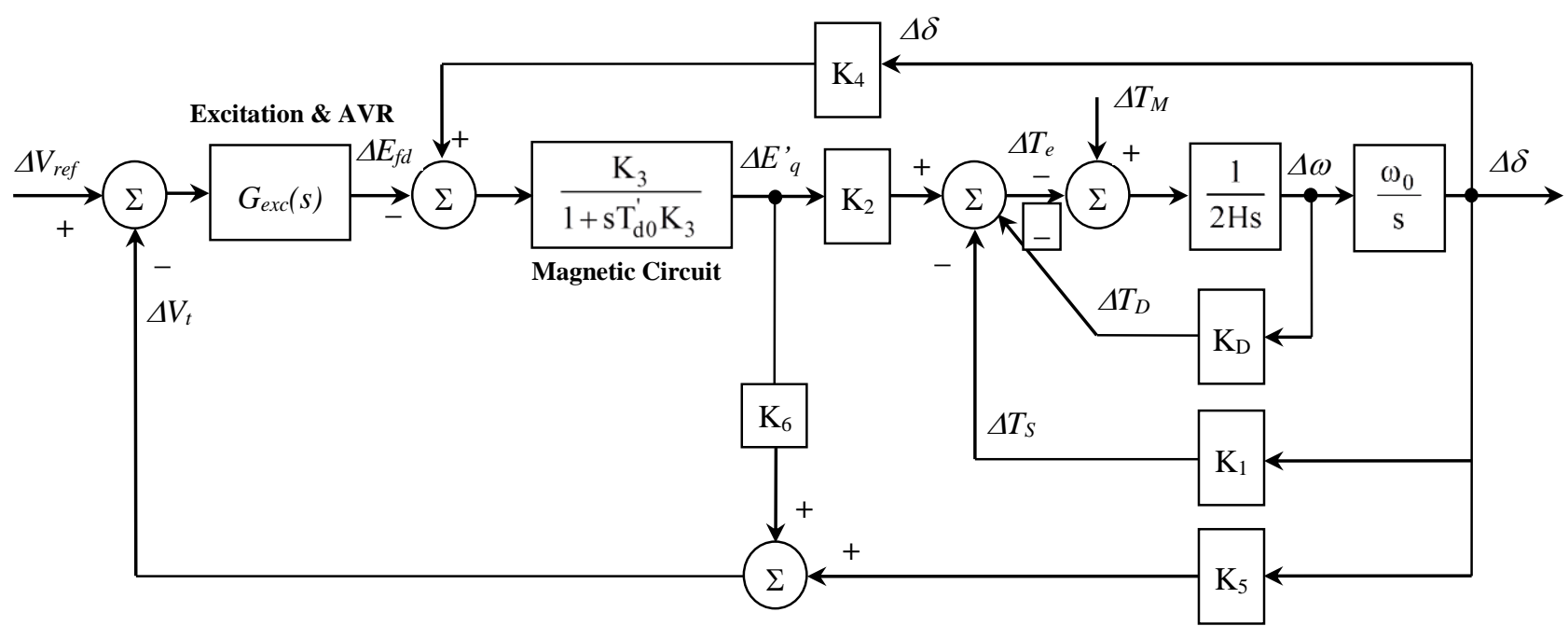

Figure 3. Block diagram of exciter controllers for grid-connected generators.

The state-space model of the generator, including exciter and AVR, is illustrated by the following equations [28]:

$\Delta \dot{E}_{q}^{\prime}=-\frac{1}{K_{3} T_{d 0}^{\prime}} \Delta E_{q}^{\prime}-\frac{K_{4}}{T_{d 0}^{\prime}} \Delta \delta+\frac{1}{T_{d 0}^{\prime}} \Delta E_{f d}$

$\Delta \dot{\delta}=\omega_{0} \Delta \omega$

$\Delta \dot{\omega}=-\frac{K_{2}}{2 H} \Delta E_{q}^{\prime}-\frac{K_{1}}{2 H} \Delta \delta-\frac{K_{D}}{2 H} \Delta \omega+\frac{1}{2 H} \Delta T_{M}$

$\Delta \dot{E}_{f d}=-\frac{K_{A} K_{6}}{T_{A}} \Delta E_{q}^{\prime}-\frac{K_{A} K_{6}}{T_{A}} \Delta \delta-\frac{1}{T_{A}} \Delta E_{f d}+\frac{K_{A}}{T_{A}} \Delta V_{r e f}$

In the form of matrices and rearrangements, we have:

$\left[\begin{array}{c}\Delta \dot{\delta} \\ \Delta \dot{\omega} \\ \Delta \dot{E}_{q}^{\prime} \\ \Delta \dot{E}_{f d}\end{array}\right]=\left[\begin{array}{cccc}0 & \omega_{0} & 0 & 0 \\ -\frac{K_{1}}{2 H} & -\frac{K_{D}}{2 H} & -\frac{K_{2}}{2 H} & 0 \\ -\frac{K_{4}}{T_{d 0}^{\prime}} & 0 & -\frac{1}{K_{3} T_{d 0}^{\prime}} & -\frac{1}{T_{d 0}^{\prime}} \\ -\frac{K_{A} K_{5}}{T_{A}} & 0 & -\frac{K_{A} K_{6}}{T_{A}} & -\frac{1}{T_{A}}\end{array}\right]\left[\begin{array}{c}\Delta \delta \\ \Delta \omega \\ \Delta E_{q}^{\prime} \\ \Delta E_{f d}\end{array}\right]+\left[\begin{array}{cc}0 & 0 \\ 1 / 2 H & 0 \\ 0 & 0 \\ 0 & K_{A} / T_{A}\end{array}\right]\left[\begin{array}{c}\Delta T_{M} \\ \Delta V_{r e f}\end{array}\right]$ 
Small signal stabilization is the ability of synchronous transmitters to maintain synchronization with each other after being subjected to minor disturbances. This is based on the ability of each generator connected to the electrical system to maintain an equilibrium of the electromagnetic torque and the mechanical torque.

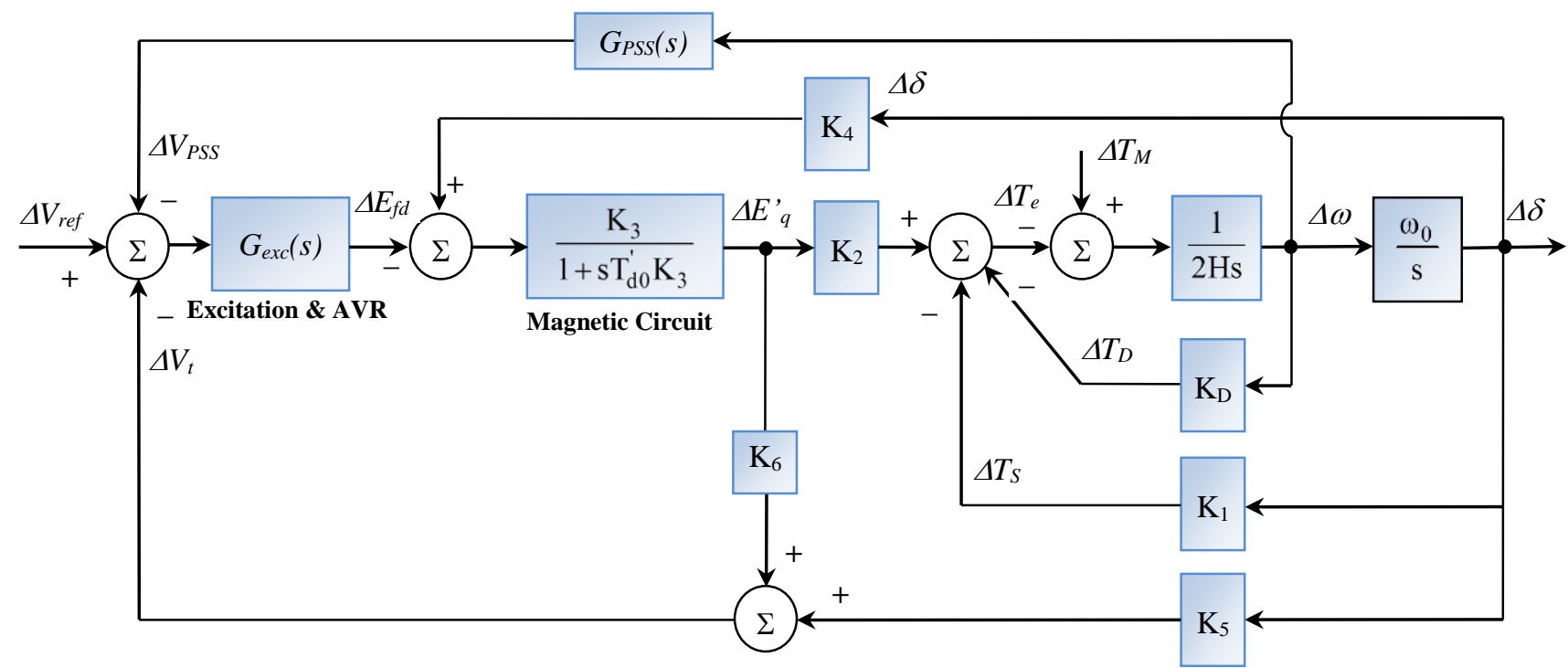

Figure 4. Block diagram of the generator with exciter, AVR, and PSS.

Figure 4 shows the linear block diagram of the generator with exciter, AVR and PSS. This is the expanded diagram of the diagram in Figure 3. The PSS input signal is speed deviation $\Delta \omega$. However, another signal, such as the dynamic power difference, $\triangle \mathrm{Pa}$, can also be used. The PSS output signal is sent to AVR. The PSS output saturation and exciter output saturation are not shown in the diagram.

\section{3- $\mathrm{RH}_{\infty}$ Optimized Controller for the Structure-Optimized PSS}

Consider the linear model of exciter, AVR and, generator [28] as shown in Figure 5.

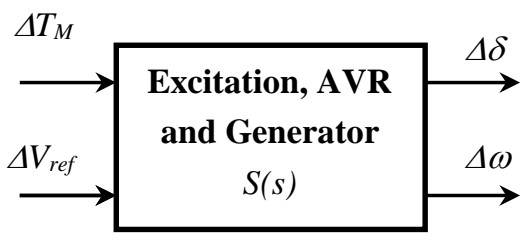

Figure 5. Linear model of exciter, AVR, and generator.

The linear transfer function of S(s) [28] has the following form:

$$
\left[\begin{array}{c}
\Delta \dot{\delta} \\
\Delta \dot{\omega} \\
\Delta \dot{E}_{q}^{\prime} \\
\Delta \dot{E}_{f d}
\end{array}\right]=\left[\begin{array}{cccc}
0 & \omega_{0} & 0 & 0 \\
-\frac{K_{1}}{2 H} & -\frac{K_{D}}{2 H} & -\frac{K_{2}}{2 H} & 0 \\
-\frac{K_{4}}{T_{d 0}^{\prime}} & 0 & -\frac{1}{K_{3} T_{d 0}^{\prime}} & -\frac{1}{T_{d 0}^{\prime}} \\
-\frac{K_{A} K_{5}}{T_{A}} & 0 & -\frac{K_{A} K_{6}}{T_{A}} & -\frac{1}{T_{A}}
\end{array}\right]\left[\begin{array}{c}
\Delta \delta \\
\Delta \omega \\
\Delta E_{q}^{\prime} \\
\Delta E_{f d}
\end{array}\right]+\left[\begin{array}{c}
0 \\
0 \\
0 \\
K_{A} / T
\end{array}\right]\left[\Delta V_{r e f}\right]+\left[\begin{array}{c}
0 \\
1 / 2 H \\
0 \\
0
\end{array}\right]\left[\Delta T_{M}\right]
$$

Or:

$$
\left[\begin{array}{c}
\Delta \dot{\delta} \\
\Delta \dot{\omega} \\
\Delta \dot{E}_{q}^{\prime} \\
\Delta \dot{E}_{f d}
\end{array}\right]=A\left[\begin{array}{c}
\Delta \delta \\
\Delta \omega \\
\Delta E_{q}^{\prime} \\
\Delta E_{f d}
\end{array}\right]+B \cdot\left[\Delta V_{r e f}\right]+C\left[\Delta T_{M}\right]
$$


The model has two inputs: the error set voltage $\Delta \mathrm{V}_{\text {ref }}$, and error torque $\Delta \mathrm{T}_{\mathrm{M}}$. The two outputs are error load angle,

$$
\Delta \delta=\left[\begin{array}{llll}
1 & 0 & 0 & 0
\end{array}\right]\left[\begin{array}{c}
\Delta \dot{\delta} \\
\Delta \dot{\omega} \\
\Delta \dot{E}_{q}^{\prime} \\
\Delta \dot{E}_{f d}
\end{array}\right]=D\left[\begin{array}{c}
\Delta \dot{\delta} \\
\Delta \dot{\omega} \\
\Delta \dot{E}_{q}^{\prime} \\
\Delta \dot{E}_{f d}
\end{array}\right]
$$

and error speed,

$$
\Delta \omega=\left[\begin{array}{llll}
0 & 1 & 0 & 0
\end{array}\right]\left[\begin{array}{c}
\Delta \dot{\delta} \\
\Delta \dot{\omega} \\
\Delta \dot{E}_{q}^{\prime} \\
\Delta \dot{E}_{f d}
\end{array}\right]=E\left[\begin{array}{c}
\Delta \dot{\delta} \\
\Delta \dot{\omega} \\
\Delta \ddot{E}_{q}^{\prime} \\
\Delta \dot{E}_{f d}
\end{array}\right]
$$

with coefficient matrices;

$$
A=\left[\begin{array}{cccc}
0 & \omega_{0} & 0 & 0 \\
-\frac{K_{1}}{2 H} & -\frac{K_{D}}{2 H} & -\frac{K_{2}}{2 H} & 0 \\
-\frac{K_{4}}{T_{d 0}^{\prime}} & 0 & -\frac{1}{K_{3} T_{d 0}^{\prime}} & -\frac{1}{T_{d 0}^{\prime}} \\
-\frac{K_{A} K_{5}}{T_{A}} & 0 & -\frac{K_{A} K_{6}}{T_{A}} & -\frac{1}{T_{A}}
\end{array}\right] ; B=\left[\begin{array}{c}
0 \\
0 \\
0 \\
K_{A} / T
\end{array}\right] ; C=\left[\begin{array}{c}
0 \\
1 / 2 H \\
0 \\
0
\end{array}\right] ; D=\left[\begin{array}{cccc}
1 & 0 & 0 & 0
\end{array}\right] ; E=\left[\begin{array}{llll}
0 & 1 & 0 & 0
\end{array}\right]
$$

The transfer function of the object $\mathrm{S}(\mathrm{s})$ is described as Equation 10:

$$
\left(\begin{array}{c}
\Delta \delta \\
\Delta \omega
\end{array}\right)=\underbrace{\left(\begin{array}{ll}
S_{11}(s) & S_{12}(s) \\
S_{21}(s) & S_{22}(s)
\end{array}\right)}_{S(s)}\left(\begin{array}{c}
\Delta T_{M} \\
\Delta V_{\text {ref }}
\end{array}\right)
$$

Where;

$$
S_{11}(s)=\frac{D C}{s I-A} ; S_{12}(s)=\frac{D B}{s I-A} ; S_{21}(s)=\frac{E C}{s I-A} ; S_{22}(s)=\frac{E B}{s I-A}
$$

When affected by the disturbance, with PSS equipped, $\Delta \delta$ is still fluctuating.

Therefore, in Trung (2012) [28], it is proposed that the design of the PSS robust controller has a block diagram as shown in Figure 6, where;

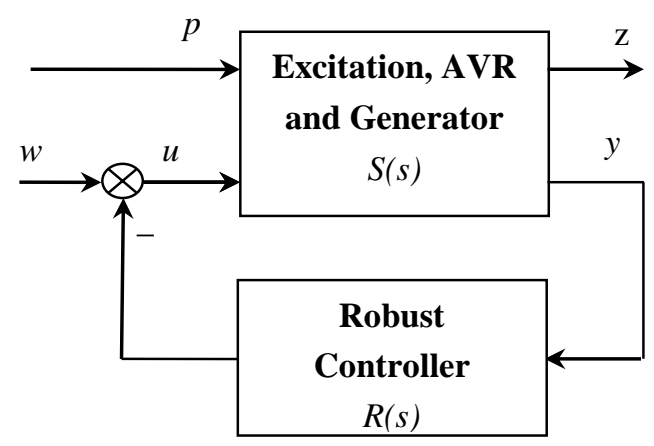

Figure 6. Block diagram of the exciter, AVR, and generator robust control system.

System state variables: $x=\left[\begin{array}{llll}\Delta \delta & \Delta \omega & \Delta E_{q}^{\prime} & \Delta E_{f d}\end{array}\right]^{T}$

Reference signal: $\omega$ 
Control signal: $u=\Delta V_{\text {ref }}-\Delta V_{P S S}$

Measured output: $y=\Delta \omega$

Output (which cannot be measured): $z=\Delta \delta$

Input (disturbance): $p=\Delta T_{M}$

The object $\mathrm{S}$ (s) in Figure 5 has the following general form:

$$
\begin{aligned}
& \dot{x}=A x+B u+C p \\
& z=D x \\
& y=E x
\end{aligned}
$$

The design of robust controller $\mathrm{RH}_{\infty}$ is according to Youla et al. (1976), Ma et al. (2014) and Gu et al. (2013) [3032], with two basic steps as follows:

1. Determine the set of all the controllers to stabilize the closed-loop (from $w$ to $y$ ) system. This set is denoted as $\mathfrak{R}(s)$.

2. Find a specific element $R(s)$ in the set $\mathfrak{R}(s)$ such that it has the slightest sensitivity to model error $\Delta S$ and noise $p$ as well as has the smallest relation $\left\|G_{p \rightarrow z}(s)\right\|_{\infty}$.

With the model parameters given in Trung (2012) [28], the following model parameters were determined:

$$
\begin{aligned}
& S_{11}(s)=\frac{41.67 s^{2}+716.3 s+1201}{s^{4}+17.46 s^{3}+103.7 s^{2}+1205 s+1786} \\
& S_{12}(s)=\frac{5458}{s^{4}+17.46 s^{3}+103.7 s^{2}+1205 s+1786} \\
& S_{21}(s)=\frac{0.1326 s^{3}+2.28 s^{2}+3.823 s-1.23 .10^{-14}}{s^{4}+17.46 s^{3}+103.7 s^{2}+1205 s+1786} \\
& S_{22}(s)=\frac{17.37 s-2.712 .10^{-12}}{s^{4}+17.46 s^{3}+103.7 s^{2}+1205 s+1786}
\end{aligned}
$$

Performing control design according to the two steps above, we obtain the controller [28] as follows:

$$
\begin{aligned}
& \mathbf{R}(s)=\frac{\mathbf{A}(s)}{\mathbf{B}(s)} \\
& \mathbf{A}(s)=-0.004867 s^{28}-0.7519 s^{27}-58.8 s^{26}-2526 s^{25}-8.35 .10^{4} s^{24}-2.128 .10^{6} s^{23}-4.383 .10^{7} s^{22} \\
& -7.542 .10^{8} s^{21}-1.108 .10^{10} s^{20}-1.411 .10^{11} s^{19}-1.527 .10^{12} s^{18}-1.544 .10^{13} s^{17}-1.341 .10^{14} s^{16}-1.032 e^{15} s^{15} \\
& -7.021 .10^{15} s^{14}-4.211 .10^{16} s^{13}-2.213 .10^{17} s^{12}-1.01 .10^{18} s^{11}-3.954 .10^{18} s^{10}-1.306 .10^{19} s^{9}-3.564 .10^{19} s^{8} \\
& -7.845 .10^{19} s^{7}-1.348 .10^{20} s^{6}-1.723 .10^{20} s^{5}-1.52 .10^{20} s^{4}-8.162 .10^{19} s^{3}-1.984 .10^{19} s^{2}+3.89 .10^{16} s-125.2 \\
& \mathbf{B}(s)=5.25 e^{-5} s^{28}+0.009786 s^{27}+0.8675 s^{26}+48.8 s^{25}+1965 s^{24}+6.056 .10^{4} s^{23}+1.49 .10^{6} s^{22}-3.018 .10^{7} s^{21} \\
& +5.14 .10^{8} s^{20}+7.483 .10^{9} s^{19}+9.425 .10^{10} s^{18}+1.035 .10^{12} s^{17}+9.968 .10^{12} s^{16}+8.432 .10^{13} s^{15}+6.266 .10^{14} s^{14} \\
& +4.079 .10^{15} s^{13}+2.314 .10^{16} s^{12}+1.134 .10^{17} s^{11}+4.74 .10^{17} s^{10}+1.66 .10^{18} s^{9}+4.762 .10^{18} s^{8}+1.085 .10^{19} s^{7} \\
& +1.891 .10^{19} s^{6}+2.399 .10^{19} s^{5}+2.062 .10^{19} s^{4}+1.065 .10^{19} s^{3}+2.479 .10^{18} s^{2}-1.59 .10^{4} s+2.945 .10^{-11}
\end{aligned}
$$

Analyzing and eliminating the matching poles and zeros of the controller, transforming the controller to normalized form, we obtain a controller with the following structure:

$$
\begin{aligned}
& \mathbf{R}(s)=\frac{\mathbf{C}(s)}{\mathbf{D}(s)} \\
& \mathbf{C}(s)=-92.89 s^{17}-1.35810^{4} s^{16}-9.111 .10^{5} s^{15}-3.727 .10^{7} s^{14}-1.042 .10^{9} s^{13}-2.124 .10^{10} s^{12}-3.286 .10^{11} s^{11} \\
& -3.971 .10^{12} s^{10}-3.825 .10^{13} s^{9}-2.963 .10^{14} s^{8}-1.836 .10^{15} s^{7}-8.929 .10^{15} s^{6}-3.315 .10^{16} s^{5}-9.091 .10^{16} s^{4} \\
& -1.768 .10^{17} s^{3}-2.22 .10^{17} s^{2}-1.279 .10^{17} s+2.036 .10^{14}
\end{aligned}
$$




$$
\begin{aligned}
& \mathbf{D}(s)=s^{17}+178.5 s^{16}+1.484 .10^{4} s^{15}+7.642 .10^{5} s^{14}+2.731 .10^{7} s^{13}+7.183 .10^{8} s^{12}+1.436 .10^{10} s^{11} \\
& +2.221 .10^{11} s^{10}+2.677 .10^{12} s^{9}+2.517 .10^{13} s^{8}+1.831 .10^{14} s^{7}+1.018 .10^{15} s^{6}+4.225 .10^{15} s^{5} \\
& +1.263 .10^{16} s^{4}+2.552 .10^{16} s^{3}+3.075 .10^{16} s^{2}+1.588 .10^{16} s
\end{aligned}
$$

Using the $17^{\text {th }}$-order controller to stabilize the generator's rotor angle, we obtained the simulation results in MatlabSimulink as follows:

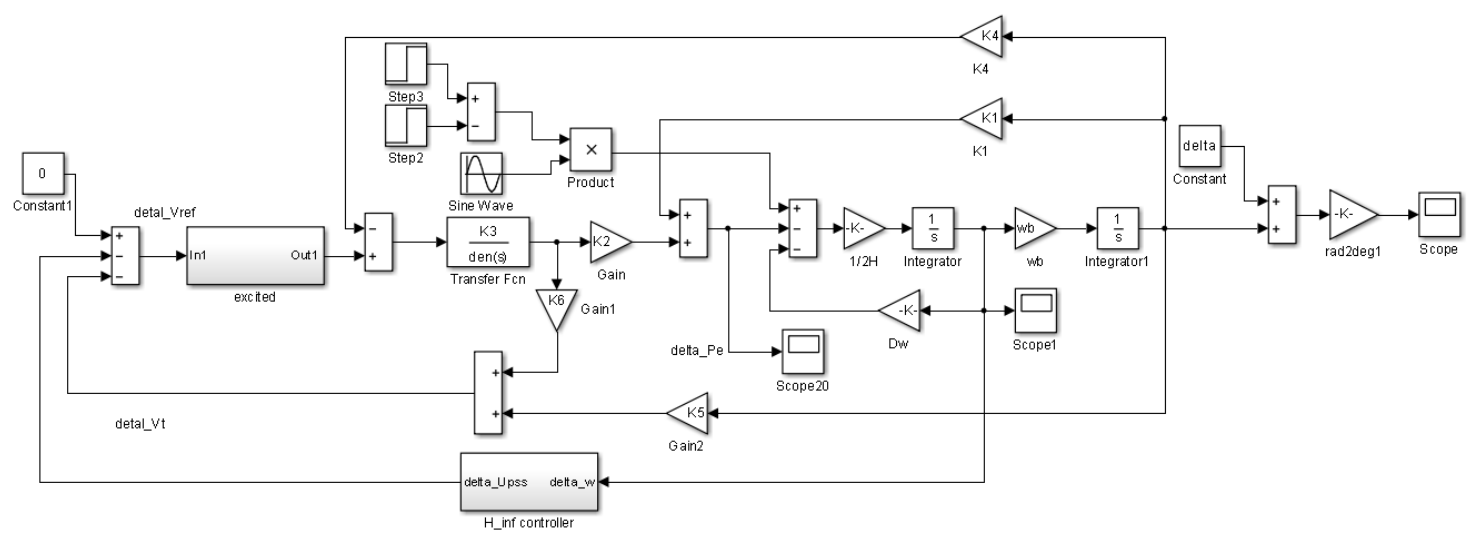

Figure 7. Simulation of the generator's rotor angle stabilization system in Matlab-Simulink.

Assume that at time $t=3 \mathrm{~s}$, the input noise appears (shown in Figure 7 by step 2, step 3 and sin wave), after a grid cycle it is lost [28]; busbar voltage $V_{s}=1$ p.u (per unit); capacity $S=0.8+i 0.6 p$. $u$; line impedance $R_{e}=0 ; X_{e}=0.1$ p.u (Figure 2)
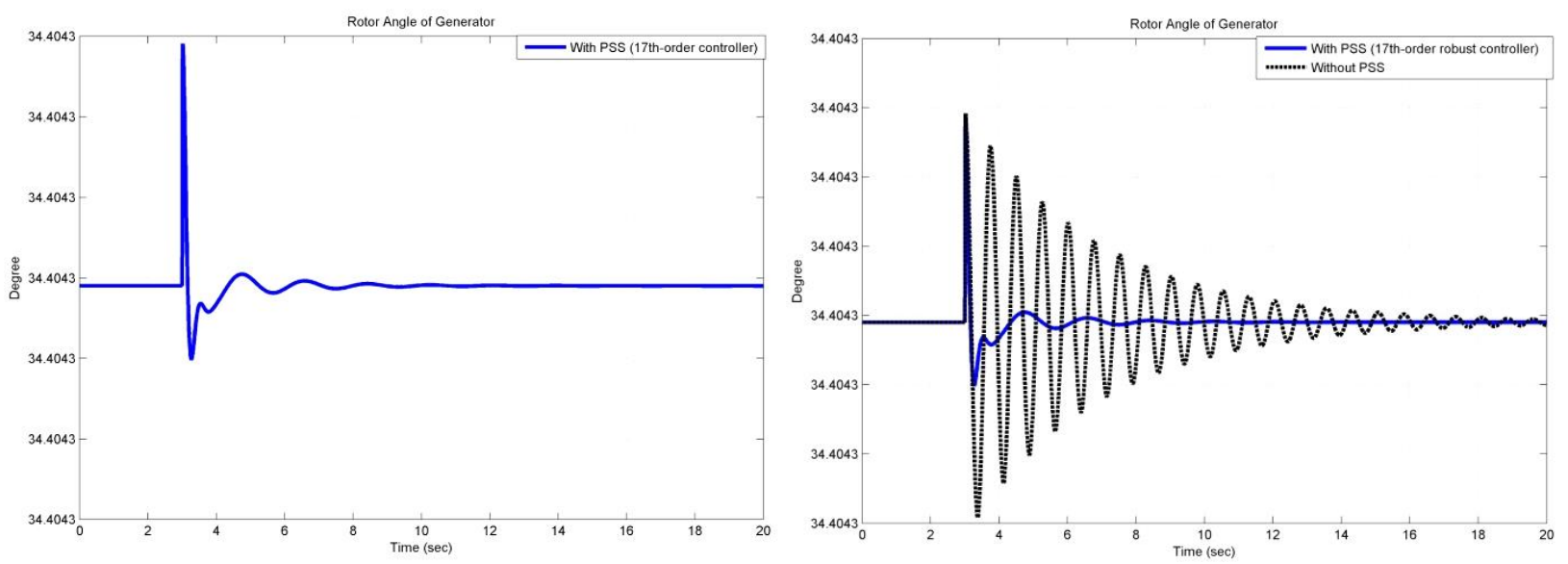

Figure 8. Generator's rotor angle response $\delta$ when using $17^{\text {th }}$-order robust controller [28].

(*) Comment: Figure 8 shows that: Without PSS, when input noise appears, the load angle will fluctuate a lot. With PSS $\left(17^{\text {th }}\right.$-order robust controller), the load angle fluctuates slightly around the working point (the number of oscillations is 5), after 5 seconds of oscillations, the control system returned the generator rotor angle to the original state. The $17^{\text {th }}$ order robust controller is capable of maintaining the stability of the generator rotor angle. However, using the $17^{\text {th }}$-order controller results in complex control program codes, which can affect the response speed of the actual control system and destabilize the system. Therefore, we aim to reduce the $17^{\text {th }}$-order controller to simplify the control program code and ensure that the actual control system always maintains a stable balance.

\section{4- Results and Discussion}

The requirements for the order reduction problem are as follows: A low-order controller has as low order as possible. The response of a control system using a low-order controller must match that of a control system using a $17^{\text {th }}$-order controller, or a control system using a low-order controller ensures stability when the system has oscillation.

To reduce the order of the controller, there are two basic solutions as follows:

Solution 1: Select the low-order controller with a fixed structure, then apply the optimal algorithms to select the loworder controller parameters so that the response of the low-order controller matches that of the high-order controller. 
Solution 2: Applying the order reduction algorithms to simplify a higher-order controller results in a set of reducedorder controllers. The lowest-order obtained controller that still satisfies the control requirements to stabilize the generator's rotor angle will be selected to replace the high-order controller.

In this paper, we choose Solution 2 to reduce the order of the $17^{\text {th }}$-order controller. Analysis of the $17^{\text {th }}$-order controller's poles shows that the $17^{\text {th }}$-order controller has a pole of zero, so to reduce the order of the $17^{\text {th }}$-order controller, it is necessary to use the order reduction algorithms for the unstable system. To reduce the order of an unstable system, there are two basic methods: direct and indirect methods.

The group of indirect methods is developed from the group of order reduction algorithms for stable systems, so they still use the mathematical tools of the order reduction algorithms for the stable system. However, these math tools cannot work directly with unstable systems. To overcome this difficulty, the indirect method group offers two ways as follows. The first method is to divide the system into two subsystems, which are stable subsystem and unstable subsystem. The order of the stable subsystem will be reduced to obtain a low-order stable subsystem. Finally, combining the low-order stable subsystem with the unstable one will receive a low-order unstable system. Finally, a low-order stable module and a low-order unstable module are integrated to obtain a low-order unstable system. Typical algorithms for this approach are the dominant pole retention algorithm (preserving dominant pole algorithm) [33], balanced truncation model reduction [34-38]. Method 2 converts the system from unstable to stable, then applies the order reduction algorithms to the stable system to obtain a stable reduced-order system, and then performs reverse transformation to transform the stable reduced-order system to the unstable reduced-order system. This group's typical algorithms can include Zilochian's balanced truncation algorithm [39], continuous-discrete mapping algorithm [40].

The direct method group, using mathematical tools, can perform direct order reduction of the unstable system without having to separate or transform the system. This group's typical algorithms are Zhou's balanced truncation algorithm [41], LQG balanced truncation algorithm [42].

Through analysis, we see that there are many solutions to reduce the order for an unstable system. Therefore, each specific order reduction problem must compare and evaluate the order reduction results between solutions to choose the appropriate solution. This article selects the most typical order reduction algorithm of the direct methods and the indirect methods. The order reduction results of these methods will be compared to determine a suitable robust low-order controller. Specifically, we choose the following algorithms: the dominant pole retention algorithm [33] (preserving dominant poles), Zhou's balanced truncation algorithm [41], Zilochian's balanced truncation algorithm [39], continuousdiscontinuous mapping algorithm [40]. Applying the selected algorithms to reduce the order of the $17^{\text {th }}$-order controller, we obtained the following results:

Table 1. The $4^{\text {th }}$-order controller.

\begin{tabular}{cc}
\hline The order reduction algorithms & The 4 $^{\text {th }}$-order controller \\
\hline Dominant pole retention algorithm [33] & $\frac{-92.89 s^{4}-1042 s^{3}-4767 s^{2}-6.205 .10^{4} s+85.25}{s^{4}+43.89 s^{3}+717.7 s^{2}+6651 s-3.366 .10^{-17}}$ \\
Zhou's balanced truncation algorithm [41] & $\frac{-92.89 s^{4}-912.8 s^{3}-6772 s^{2}-4.801 .10^{4} s-1.106 .10^{4}}{s^{4}+42.1 s^{3}+701.4 s^{2}+6869 s+1312}$ \\
Zilochian's balanced truncation algorithm [39] & $\frac{-92.89 s^{4}-424 s^{3}-7535 s^{2}-2.483 .10^{4} s-3.513 .10^{4}}{s^{4}+36.7 s^{3}+552.5 s^{2}+4720 s+3923}$ \\
Continuous-discontinuous mapping algorithm [40] & $\frac{-92.07 s^{4}-276.2 s^{3}-7650 s^{2}-1.79 .10^{4} s-6.131 .10^{4}}{s^{4}+34.16 s^{3}+522.7 s^{2}+3701 s+7637}$ \\
\hline
\end{tabular}

The step responses and the bode responses of the $4^{\text {th }}$-order controller and $17^{\text {th }}$-order controller are plotted in Figures 9 and 10 as follows;

Figures 9 and 10 show that the $4^{\text {th }}$-order controller, according to the dominant pole retention algorithm, has the step response and the bode response matching the $17^{\text {th }}$-order controller. Meanwhile, other techniques obtain a minor deviation in the step response and the bode response compared to the $17^{\text {th }}$-order controller. Thus, it is possible to use the $4^{\text {th }}$-order controller according to the dominant pole retention algorithm to replace the $17^{\text {th }}$-order controller. 

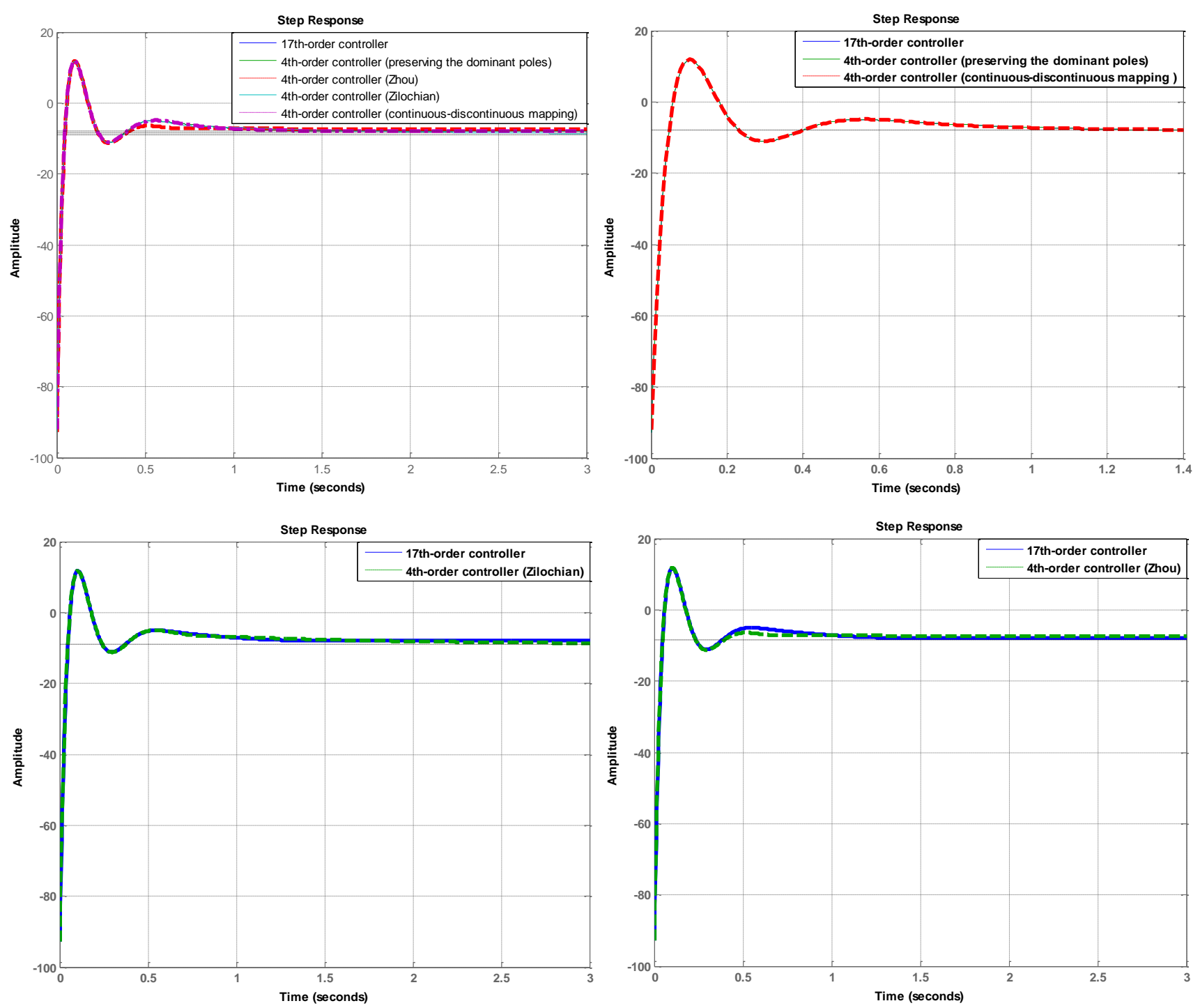

Figure 9. Step responses of the $4^{\text {th }}$-order controller and the $17^{\text {th }}$-order controller.
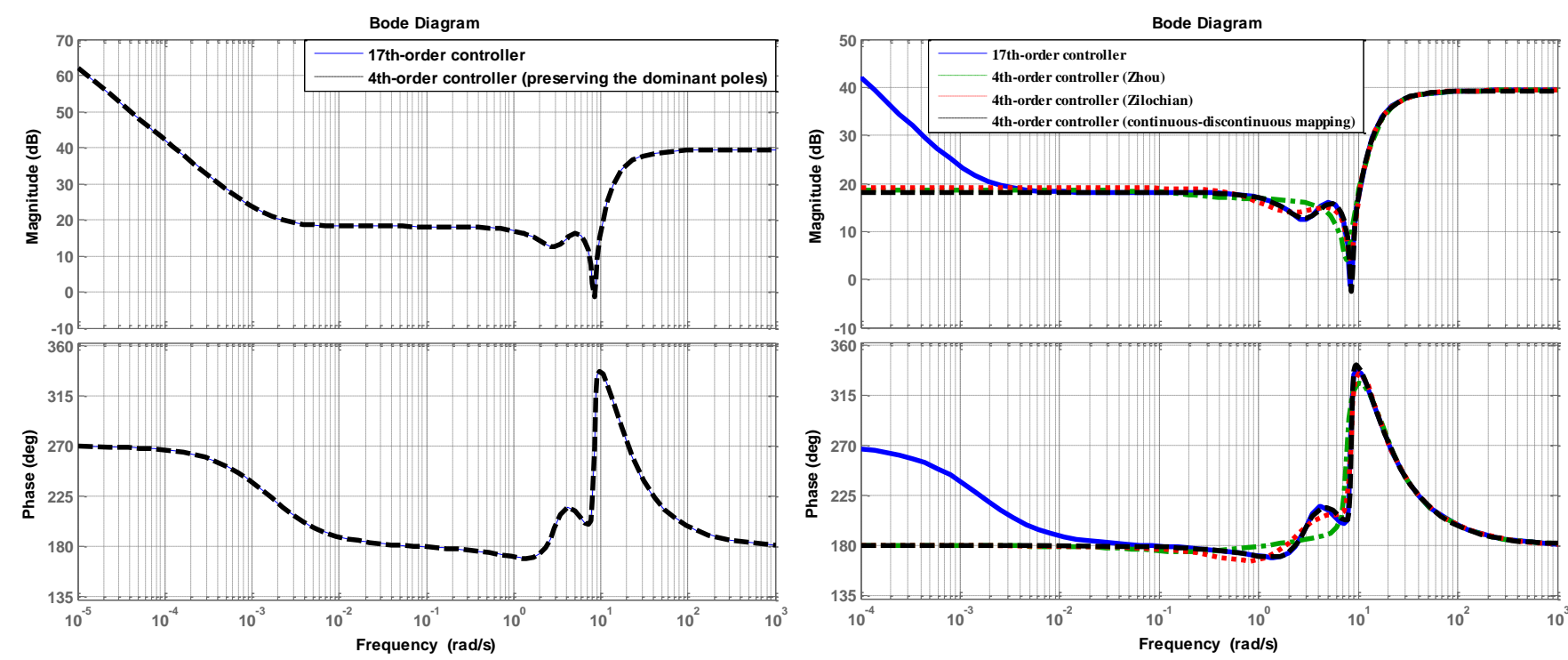

Figure 10. Bode response of the $4^{\text {th }}$-order controller and the $17^{\text {th }}$-order controller. 
Table 2. The $3^{\text {rd }}$-order controller.

\begin{tabular}{lc}
\hline \multicolumn{1}{c}{ The order reduction algorithms } & The $\mathbf{3}^{\text {rd }}$-order controller \\
\hline Dominant pole retention algorithm [33] & $\frac{-92.89 s^{3}+3184 s^{2}-5.034 .10^{4} s-1.468 .10^{6}}{s^{3}-26.29 s^{2}+548.9 s+1.954 .10^{4}}$ \\
Zhou's balanced truncation algorithm [41] & $\frac{-92.89 s^{3}-906.5 s^{2}-6518 s-4.763 .10^{4}}{s^{3}+42.03 s^{2}+696.4 s+6757}$ \\
Zilochian's balanced truncation algorithm [39] & $\frac{-92.89 s^{3}-407.5 s^{2}-6853 s-2.386 .10^{4}}{s^{3}+736.52 s^{2}+538.8 s+4446}$ \\
Continuous-discontinuous mapping algorithm [40] & $\frac{-93.23 s^{3}-921.3 s^{2}-6746 s-4.933 .10^{4}}{s^{3}+42.65 s^{2}+693.6 s+7098}$ \\
\hline
\end{tabular}

The step responses and the bode responses of the $3^{\text {rd }}$-order controller and $17^{\text {th }}$-order controller are plotted in Figures 11 and 12:
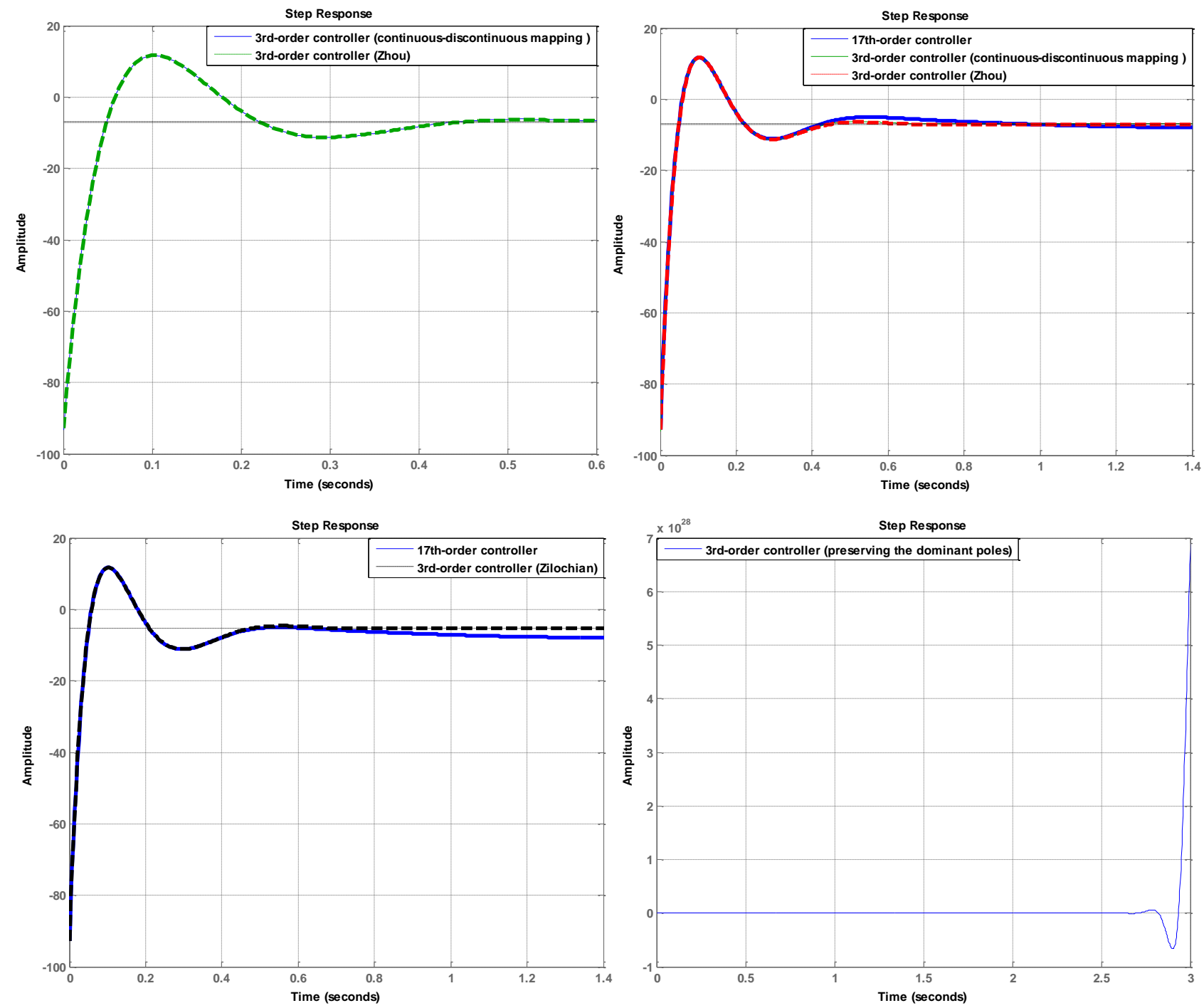

Figure 11. Step responses of the 3rd order controller and the 17th order controller.

From Figure 11, it can be seen that the step response of the $3^{\text {rd }}$-order controller according to Zhou's balanced truncation algorithm coincides with those according to the continuous-discontinuous mapping algorithm. These two responses have a slight deviation from that of the $17^{\text {th }}$-order controller. Also, compared to the step response of the $17^{\text {th }}$ order controller, the step response of the $3^{\text {rd }}$-order controller according to Zilochian's balanced truncation algorithm has a slight deviation. In contrast, the $3^{\text {rd }}$-order controller's step response according to the dominant pole retention algorithm has a considerable variation. 

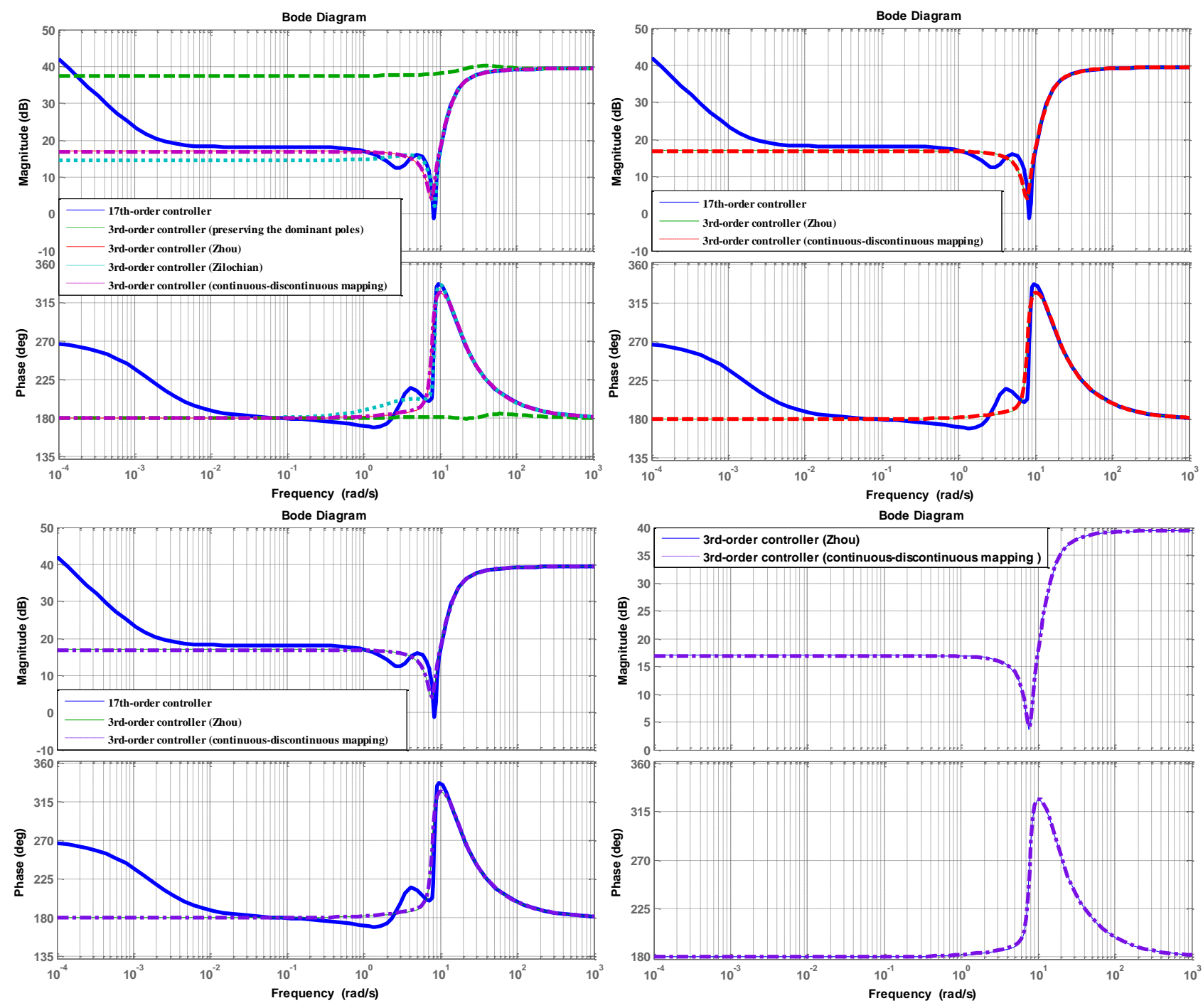

Figure 12. Bode responses of the $3^{\text {rd }}$-order controller and the $17^{\text {th }}$-order controller.

From Figure 12, it can be seen that the bode response of the $3^{\text {rd }}$-order controller according to Zhou's balanced truncation algorithm coincides with those according to the continuous-discontinuous mapping algorithm. These two responses have a slight deviation from that of the $17^{\text {th }}$-order controller. Compared to the bode response of the $17^{\text {th }}$-order controller, the bode response of the $3^{\text {rd }}$-order controller, according to Zilochian's balanced truncation algorithm, has a slight deviation. In contrast, the $3^{\text {rd }}$-order controller's bode response according to the dominant pole retention algorithm has a huge deviation.

Thus, if we accept minor errors, we can use a $3^{\text {rd }}$-order controller according to the continuous-discontinuous mapping algorithm or Zhou's balanced truncation algorithm to replace the $17^{\text {th }}$-order controller.

Table 3. The $2^{\text {nd }}$-order controller.

\begin{tabular}{lc}
\hline \multicolumn{1}{c}{ The order reduction algorithms } & The $2^{\text {nd }}$-order controller \\
\hline Dominant pole retention algorithm [33] & $\frac{-92.89 s^{2}-842.8 s-5288}{s^{2}+11.74 s-67.7}$ \\
Zhou's balanced truncation algorithm [41] & $\frac{-92.89 s^{2}+521.2 s-4377}{s^{2}+26.66 s^{2}+178.7}$ \\
Zilochian's balanced truncation algorithm [39] & $\frac{-92.89 s^{2}+220.1 s-4576}{s^{2}+29.11 s^{2}+336.2}$ \\
Continuous-discontinuous mapping algorithm [40] & $\frac{-87.06 s^{2}-136.2 s-3781}{s^{2}+27.58 s+519.3}$ \\
\hline
\end{tabular}


The step responses and the bode responses of the $2^{\text {nd }}$-order controller and $17^{\text {th }}$-order controller are plotted in Figures 13 and 14;
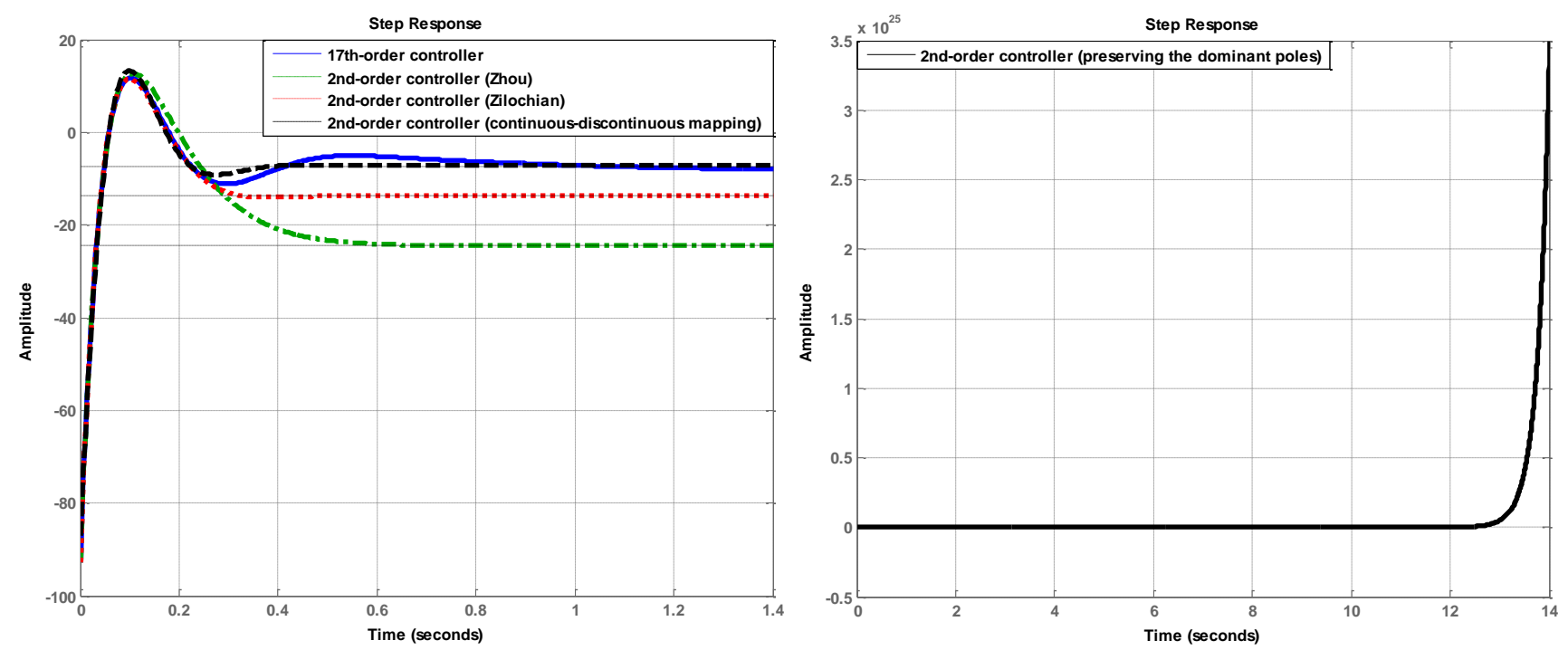

Figure 13. Step responses of the $2^{\text {nd }}$-order controller and the $17^{\text {th }}$-order controller.

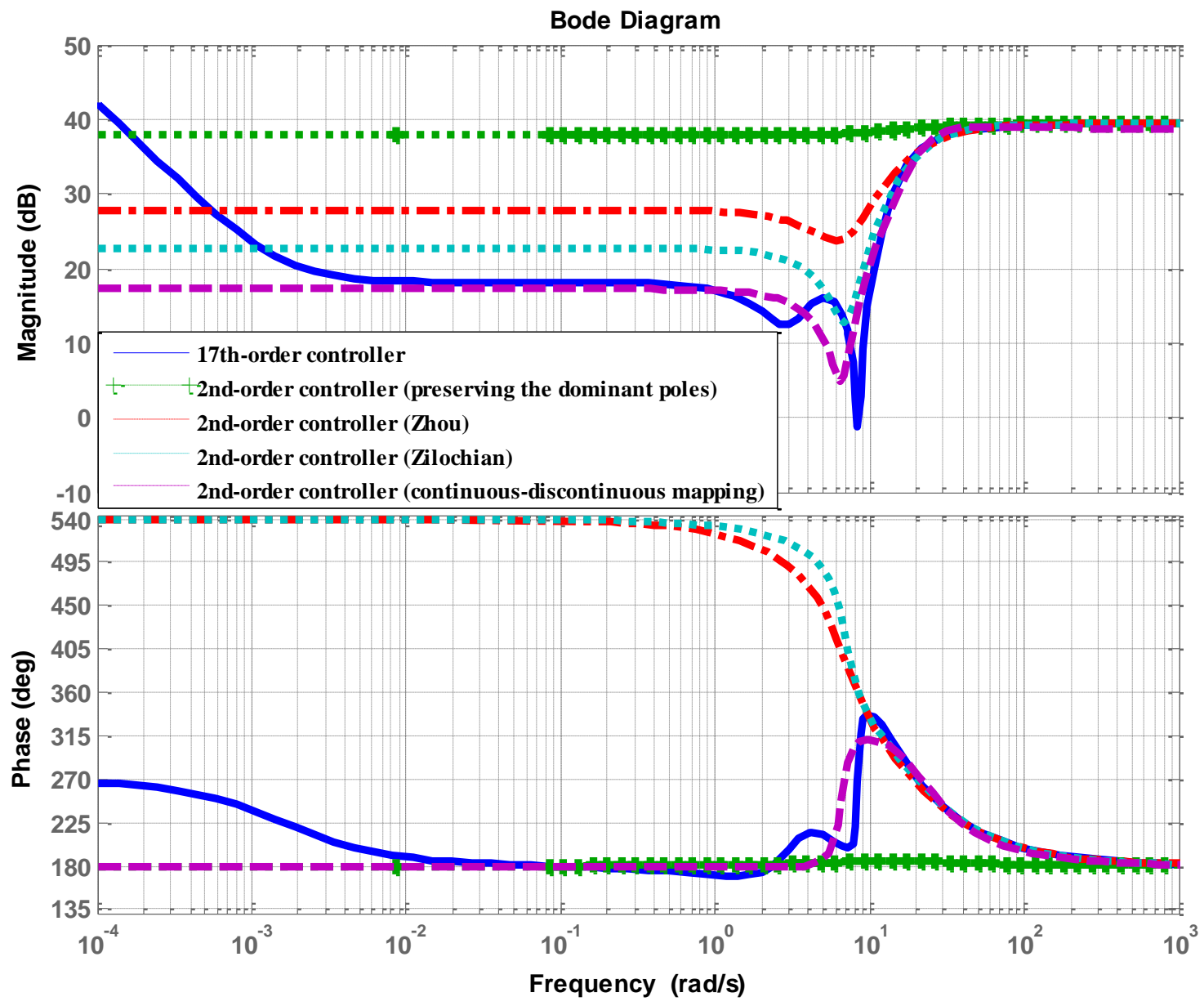

Figure 14. Bode responses of the $2^{\text {nd }}$-order controller and the $17^{\text {th }}$-order controller.

From Figures 13 and 14, we see that: Compared with the responses of the $17^{\text {th }}$-order controller, the bode response and the step response of the $2^{\text {nd }}$-order controller according to the continuous-discontinuous mapping algorithm have the smallest deviation compared to those according to other algorithms. The bode response of the $2^{\text {nd }}$-order controller according to the dominant pole retention algorithm has a huge deviation compared to the bode response of the $17^{\text {th }}$-order controller. Thus, if minor errors are acceptable, a $2^{\text {nd }}$-order controller according to the continuous-discontinuous mapping algorithm can be used to replace the $17^{\text {th }}$-order controller. 
Conclusion: Suppose we aim to obtain a low-order controller with the slightest deviation (deviation of step and bode responses) compared to the $17^{\text {th }}$-order controller. In that case, we can choose the $4^{\text {th }}$-order controller according to the dominant pole retention algorithm. Suppose you desire to receive a low-order controller with the smallest order and accept minor deviations (deviation of step and bode response) compared to a $17^{\text {th }}$-order controller. In that case, we can choose a $2^{\text {nd }}$-order controller according to the continuous-discontinuous mapping algorithm.

\section{(*) Compare the results of the controller order reduction with the results in Trung (2012) [28]}

In Trung (2012) [28], the author performs order reduction of the $28^{\text {th }}$-order robust controller and obtains the $6^{\text {th }}$-order robust controller as follows;

$$
\mathrm{W}_{6}(\mathrm{~s})=\frac{-92.89 \mathrm{~s}^{6}-485.1 \mathrm{~s}^{5}-7567 \mathrm{~s}^{4}-2.809 .10^{4} \mathrm{~s}^{3}-3.099 .10^{4} \mathrm{~s}^{2}+53,51 \mathrm{~s}-1.722 .10^{-13}}{\mathrm{~s}^{6}+37.5 \mathrm{~s}^{5}+566.9 \mathrm{~s}^{4}+5136 \mathrm{~s}^{3}+3410 \mathrm{~s}^{2}-2.187 .10^{-11} \mathrm{~s}+3.506 .10^{-26}}
$$

The step responses and the bode responses of $6^{\text {th }}$-order controller [28], $2^{\text {nd }}$-order controller and $4^{\text {th }}$-order controller are plotted in Figures 15 and 16;
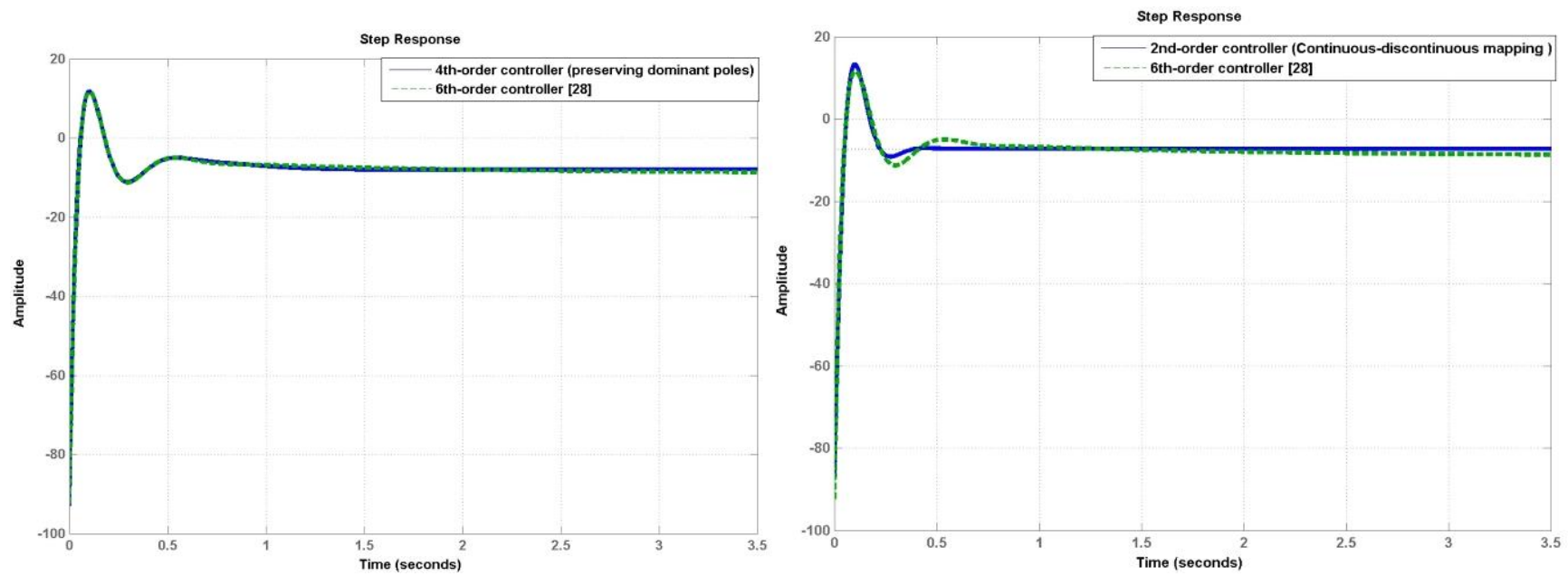

Figure 15. Step responses of the $6^{\text {th }}$-order controller, $4^{\text {th }}$-order controller and $2^{\text {nd }}$-order controller.

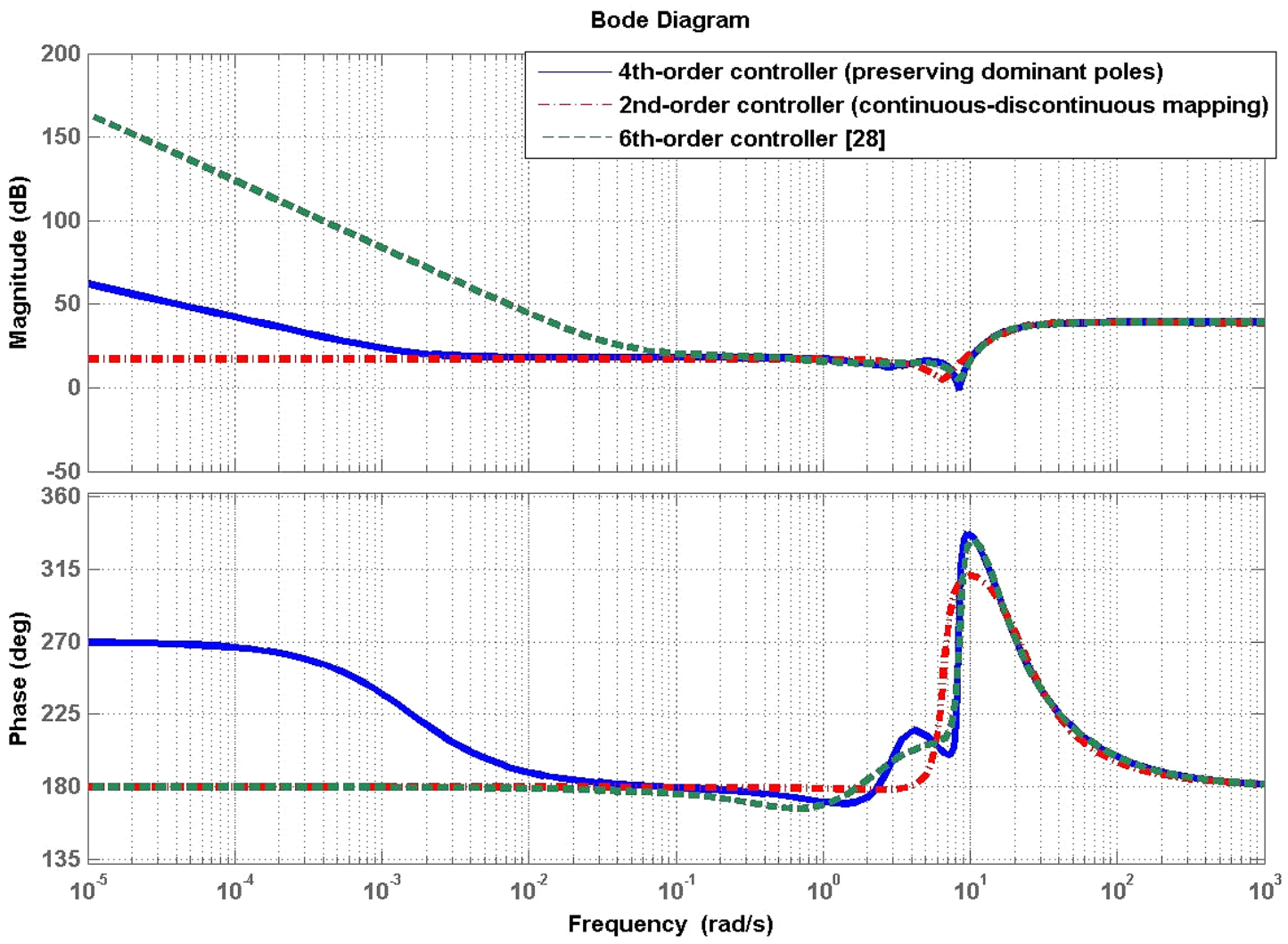

Figure 16. Bode responses of the $6^{\text {th }}$-order controller, $4^{\text {th }}$-order controller and $2^{\text {nd }}$-order controller. 
From Figure 15, we see: The step response of the $6^{\text {th }}$-order controller [28] almost coincides with the step response of the $4^{\text {th }}$-order controller according to the dominant pole retention algorithm. There is a difference between the step response of the $2^{\text {nd }}$ order controller according to the continuous-discrete conversion algorithm and the step response of the 6th order controller [28], in the time interval from $t=0.25 \mathrm{~s} \div 1 \mathrm{~s}$ and $\mathrm{t} \geq 3.5 \mathrm{~s}$, but the difference is small. For other time periods, the step response of the $2^{\text {nd }}$-order controller according to the continuous-discrete conversion algorithm matches the step response of the $6^{\text {th }}$-order controller [28].

From Figure 16, for amplitude characteristic, we see that: In the frequency range from $\omega=0.0973 \div 4,07 \mathrm{rad} / \mathrm{s}, \omega \geq$ $10.3 \mathrm{rad} / \mathrm{s}$, the three controllers' amplitude characteristics coincide; In other frequency regions, the amplitude characteristics of the three controllers have deviation. Especially in the low-frequency region, the amplitude characteristic of the three controllers is considerable. For phase characteristics: In the frequency region $\omega \geq 15.5 \mathrm{rad} / \mathrm{s}$, the frequency phase characteristics of the three controllers are almost identical; In other frequency regions, the frequency phase characteristics of the three controllers are different.

Overall, the $2^{\text {nd }}$ and $4^{\text {th }}$-order controllers selected to replace controller 17 th order controller have smaller orders than those of the $6^{\text {th }}$-order controllers in Trung (2012) [28]. A lower controller level results in simpler control program code, better response time, and real-time controllability.

\section{4-1- Simulation Results}

To evaluate the reduced-order controllers' efficiency, we use the reduced-order controllers selected in Section Controller reduction to control the generator's rotor angle stabilization PSS system (the rotor angle control system of the generator). Using the $4^{\text {th }}$-order controller according to the dominant pole retention algorithm to control the generator's rotor angle stabilization PSS system, we obtained the simulation results, as shown in Figure 15.

Assume that at time $\mathrm{t}=3 \mathrm{~s}$, the input noise appears, after a grid cycle it is lost.

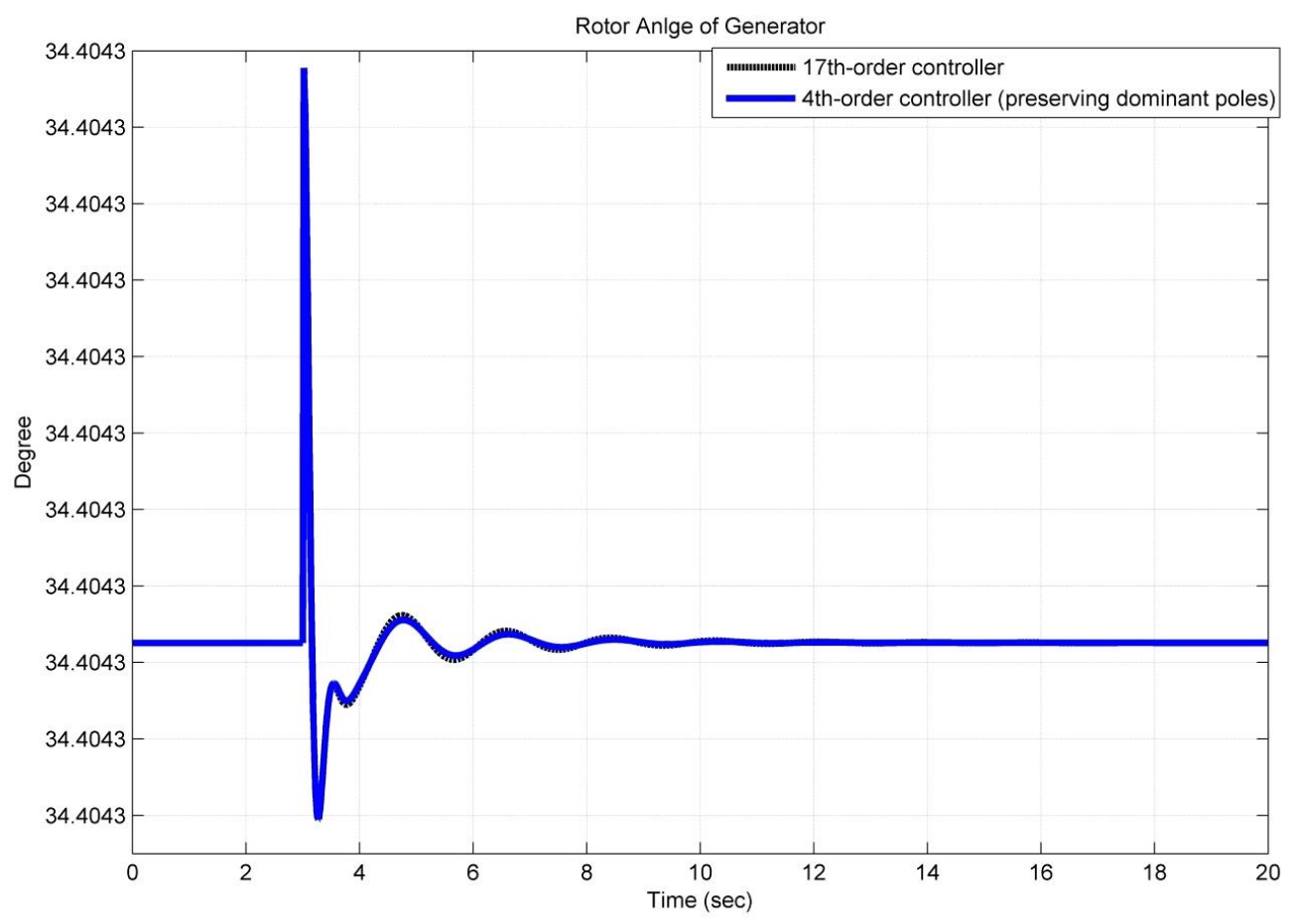

Figure 17. The rotor angle response of generator when using $17^{\text {th }}$-order controller and the $4^{\text {th }}$-order controller.

It can be seen from Figure 17 that: after 5 seconds of oscillations (the number of oscillations is 5), the control system using the $4^{\text {th }}$-order controller returned the generator rotor angle to the original state. The $4^{\text {th }}$-order robust controller is capable of maintaining the stability of the generator rotor angle. Comparison of the rotor angular response of the generator when using a $4^{\text {th }}$-order robust controller and when using $17^{\text {th }}$-order robust controller shows that: the two rotor angular responses of the generator are coincident in the time interval from $t=3$ to $3.5 \mathrm{~s}$ and $\mathrm{t}>11 \mathrm{~s}$; The two rotor angular responses of the generator have minimal deviations in the time interval from $t=3.5 \mathrm{~s}-11 \mathrm{~s}$. The rotor angle response of generator when using the $4^{\text {th }}$-order controller almost coincides with the rotor angle response of generator when using the $17^{\text {th }}$-order controller. 
Using the $2^{\text {nd }}$-order controller according to the continuous-discontinuous mapping algorithm to control the rotor angle of generator, we obtained the simulation results as follows:

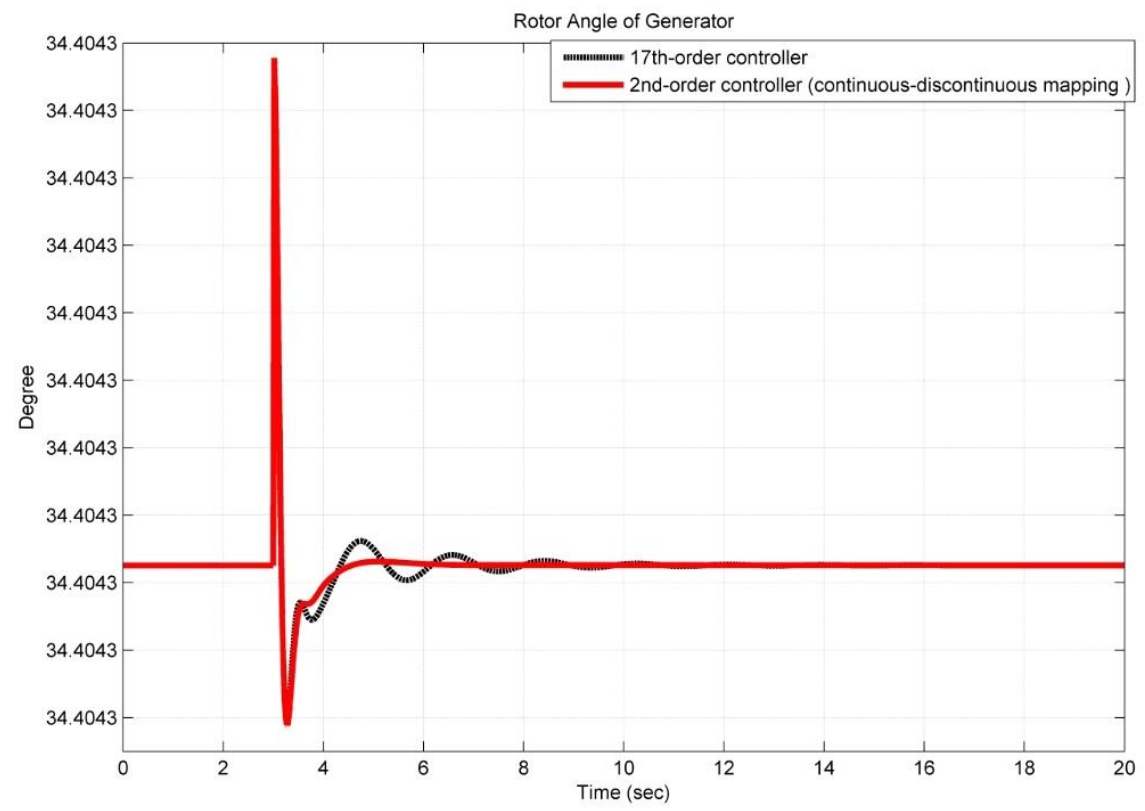

Figure 18. The rotor angle response of generator when using $17^{\text {th }}$-order controller and $2^{\text {nd }}$-order controller.

From Figure 18, we see that using a $2^{\text {nd }}$-order robust controller according to the continuous-discontinuous mapping algorithm, the rotor angle control system of the generator returns the rotor angle to its original state after $3 \mathrm{~s}$ (the number of oscillations is 2 ). Using a $17^{\text {th }}$-order controller, the rotor angle control system of the generator returns the rotor angle to its original state after $5 \mathrm{~s}$ (the number of oscillations is 5). Comparison of the rotor angular response of the generator when using a $2^{\text {nd }}$-order robust controller and when using a $17^{\text {th }}$-order robust controller shows that: the two rotor angular responses of the generator are coincident in the time interval from $\mathrm{t}=3$ to $3.58 \mathrm{~s}$ and $\mathrm{t}>13 \mathrm{~s}$; The two rotor angular responses of the generator have deviations in the time interval from $t=3.58 \mathrm{~s}-13 \mathrm{~s}$. The rotor angle response of generator when using the $2^{\text {nd }}$-order robust controller deviates from that when using the $17^{\text {th }}$-order controller. The response quality of the rotor angle control system of the generator when using the $2^{\text {nd }}$-order controller is better (shorter response time, less oscillations) compared to the rotor angle control system of the generator using a $17^{\text {th }}$-order controller. Thus, the reduced-order controllers chosen to replace the $17^{\text {th }}$-order controller all meet the generator's rotor angle stabilization system requirements.

(*) Compare with the results obtained in Trung (2012) [28];

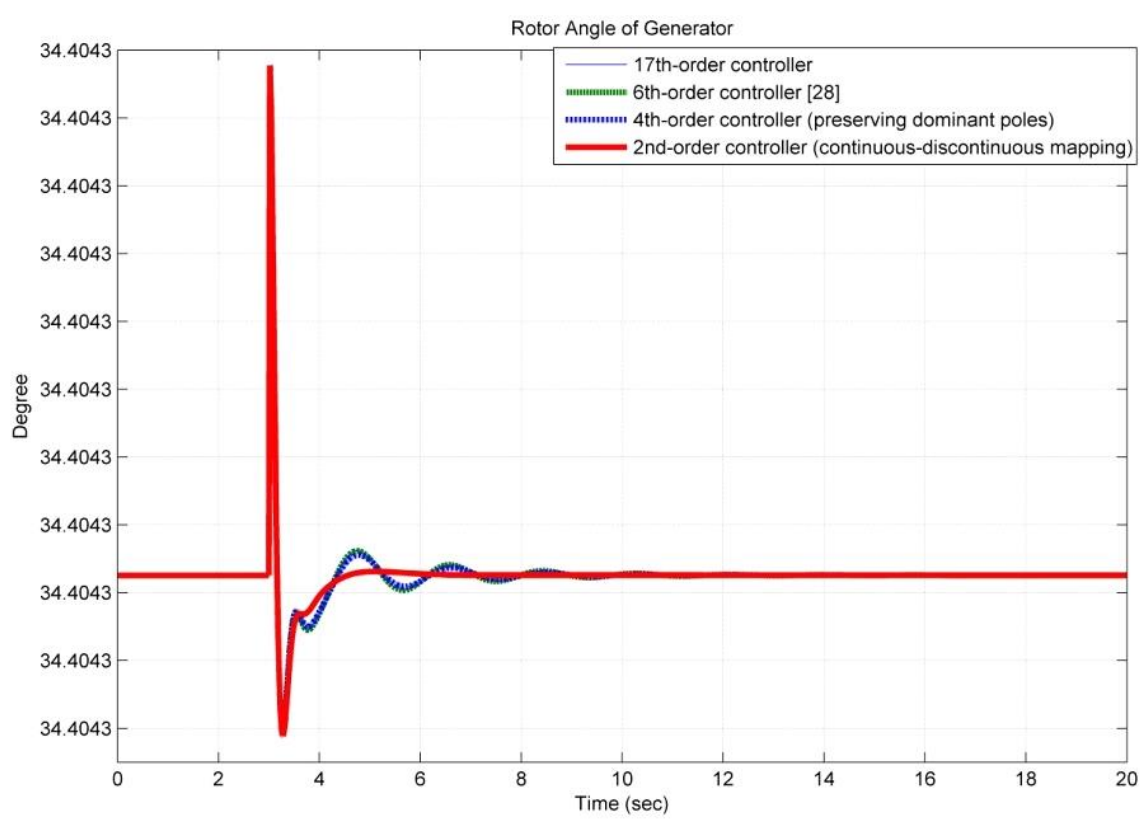

Figure 19. Generator rotor angle response when using $17^{\text {th }}$ order robust controller and reduced-order controllers. 
When using the $6^{\text {th }}$-order controller obtained in in Trung (2012) [28], the rotor angle stabilization system of the generator after $5 \mathrm{~s}$ (the number of oscillations is 2) brought the rotor angle back to the original working point. The $6^{\text {th }}$ order robust controller is capable of maintaining a stable generator rotor angle. The generator rotor angle response when using a 6th order controller according to Trung (2012) [28] coincides with those of using a $17^{\text {th- }}$ order robust controller and almost coincides with those of using the $4^{\text {th }}$-order controller according to the preserving dominant poles algorithm.

Thus, all three controllers $\left(6^{\text {th }}\right.$-order controller [28], $4^{\text {th- }}$ order controller according to the preserving dominant poles algorithm, $2^{\text {nd }}$ order controller according to the continuous-discrete conversion algorithm) can maintain a stable rotor angle and be selected to replace the $17^{\text {th }}$-order controller. Comparing the performance of rotor angle response using three controllers, we see that the $2^{\text {nd }}$-order controller for the best rotor angle response quality. However, the $4^{\text {th }}$-order controller, according to the preserving dominant poles algorithm, and the $2^{\text {nd }}$-order controller according to the continuous-discrete conversion algorithm have smaller orders than the order of the $6^{\text {th }}$-order controller [28], so it will bring more advantages to the real-time control system.

\section{5- Conclusion}

The paper has introduced a model of the generator's rotor angle stabilization PSS system according to the theory of $\mathrm{RH}_{\infty}$. A high-order $\mathrm{RH}_{\infty}$ robust controller has been designed to keep the rotor angle of the generator stable with minor disturbances. These minor disturbances are caused by a lack of damping torque, change in load, or change in a generator during operation. However, high-order robust controllers often cause many difficulties in practical applications. The paper has implemented order reduction of the high-order robust controller to overcome this disadvantage according to model order reduction algorithms. Analysis of the high-order controller poles shows that the high-order robust controller has a zero pole, so to reduce the order of the high-order robust controller, it is necessary to use model order reduction algorithms for unstable systems. The article has implemented order reduction of high-order controllers by two basic methods for unstable systems, direct and indirect methods. Through simulation, evaluation, comparison of the reducedorder controllers according to two model order reduction methods, we have selected the most suitable low-order robust controller $\left(4^{\text {th }}\right.$-order and $2^{\text {nd }}$-order robust controllers) to replace high-order robust controllers. Simulation results of the generator's rotor angle stabilization PSS system using reduced-order controllers show that: The system stabilizes the rotor angle with equivalent response times $\left(4^{\text {th }}\right.$-order controller according to the dominant pole retention algorithm) and smaller ( $2^{\text {nd }}$-order controller according to the continuous-discontinuous mapping algorithm) compared to when using the high-order controller. In the next studies, we will use optimal algorithms to find low-order robust controllers that meet the requirements of the generator's rotor angle stability control problem.

\section{6- Declarations}

\section{6-1-Author Contributions}

V.N.K. was originally responsible for conceptualization, methodology, simulation and prepared the original draft of the article. V.N.K. and N.H.T. verified the simulation data, data curation, investigation, and draft writing. N.H.Q. contributes a formal analysis of review, editing, and supervision. All authors have read and agreed to the published version of the manuscript.

\section{6-2-Data Availability Statement}

This publication is supported by multiple datasets, which are available at locations cited in the reference section.

\section{6-3-Funding}

This research was funded by Thai Nguyen University of Technology, 666, 3/2 Street, Tich Luong Ward, Thai Nguyen City, Viet Nam.

\section{6-4- Conflicts of Interest}

The authors declare that there is no conflict of interests regarding the publication of this manuscript. In addition, the ethical issues, including plagiarism, informed consent, misconduct, data fabrication and/or falsification, double publication and/or submission, and redundancies have been completely observed by the authors.

\section{7- References}

[1] Basler, M.J., and R.C. Schaefer. "Understanding Power System Stability." 58th Annual Conference for Protective Relay Engineers, (2005). doi:10.1109/cpre.2005.1430421.

[2] Shankar, R., and P. Kundur. "Power system stability and control II." New York, McGraw-Hill Books (1994): 581.

[3] P. Kundur, J. Paserba and et al., "Definition and Classification of Power System Stability IEEE/CIGRE Joint Task Force on Stability Terms and Definitions." IEEE Transactions on Power Systems 19, no. 3 (August 2004): 1387-1401. doi:10.1109/tpwrs.2004.825981. 
[4] Snyder, A.F., N. Hadjsaid, D. Georges, L. Mili, A.G. Phadke, O. Faucon, and S. Vitet. "Inter-Area Oscillation Damping with Power System Stabilizers and Synchronized Phasor Measurements." POWERCON '98. International Conference on Power System Technology. Proceedings (Cat. No.98EX151) (1998). doi:10.1109/icpst.1998.729193.

[5] Prasertwong, K., N. Mithulananthan, and D. Thakur. "Understanding Low-Frequency Oscillation in Power Systems." The International Journal of Electrical Engineering \& Education 47, no. 3 (July 2010): 248-262. doi:10.7227/ijeee.47.3.2.

[6] Rogers, Graham. "Power System Oscillations” Kluwer, Norwell, MA (2000). doi:10.1007/978-1-4615-4561-3.

[7] Chen, S. "Hळ Optimisation-Based Power System Stabiliser Design." IEE Proceedings - Generation, Transmission and Distribution 142, no. 2 (1995): 179-184. doi:10.1049/ip-gtd:19951711.

[8] Jayapal, R., and J. K. Mendiratta. "Design \& Simulation of Robust $\mathrm{H}_{\infty}$ Control Based Power System Stabilizer for SMIB models." International Journal of Computer Science and Network Security 9, no. 11 (2009): 135-149.

[9] J. C. Doyle, K. Glover, P. P. Khargonekar, B. A. Francis, "State-space solutions to standard H2 and RHळ control problems," IEEE Trans. Automat. Contr 34, no. 8, (1989): 831-847.

[10] Hardiansyah, Seizo Furuya, and Juichi Irisawa. "LMI-Based Robust H2 Controller Design for Damping Oscillations in Power Systems.” IEEJ Transactions on Power and Energy 124, no. 1 (2004): 113-120. doi:10.1541/ieejpes.124.113.

[11] Chen, S., and O.P. Malik. "Power System Stabilizer Design Using $\mu$ Synthesis.” IEEE Transactions on Energy Conversion 10 , no. 1 (March 1995): 175-181. doi:10.1109/60.372584.

[12] Rios, M., N. Hadjsaid, R. Feuillet, and A. Torres. "Power Systems Stability Robustness Evaluation by $\mu$ Analysis." IEEE Transactions on Power Systems 14, no. 2 (May 1999): 648-653. doi:10.1109/59.761893.

[13] Mendiratta, J. K., and R. Jayapal. "Hळ loop shaping based robust power system stabilizer for three machine power system." International Journal of Computer Applications 1 (2010): 106-112.

[14] Skogestad, Sigurd, and Ian Postlethwaite. "Multivariable feedback control: analysis and design.” Vol. 2. , John Wiley and Sons, (2007).

[15] Dehghani, M., and S.K.Y. Nikravesh. "Robust Tuning of PSS Parameters Using the Linear Matrix Inequalities Approach.” 2007 IEEE Lausanne Power Tech (July 2007). doi:10.1109/pct.2007.4538337.

[16] Gahinet, Pascal, and Pierre Apkarian. “A Linear Matrix Inequality Approach to $\mathrm{H}_{\infty}$ Control.” International Journal of Robust and Nonlinear Control 4, no. 4 (1994): 421-448. doi:10.1002/rnc.4590040403.

[17] Hung-Chi Tsai, Chia-Chi Chu, and Yung-Shan Chou. "Robust Power System Stabilizer Design for an Industrial Power System in Taiwan Using Linear Matrix Inequality Techniques.” IEEE Power Engineering Society General Meeting, (2004). doi:10.1109/pes.2004.1373179.

[18] Zhang, P., and A.H. Coonick. "Coordinated Synthesis of PSS Parameters in Multi-Machine Power Systems Using the Method of Inequalities Applied to Genetic Algorithms." IEEE Transactions on Power Systems 15, no. 2 (May 2000): 811-816. doi:10.1109/59.867178.

[19] Peng, Shan, and Qingzi Wang. "Power System Stabilizer Parameters Optimization Using Immune Genetic Algorithm." IOP Conference Series: Materials Science and Engineering 394 (August 8, 2018): 042091. doi:10.1088/1757-899x/394/4/042091.

[20] Zhang, Y., G.P. Chen, O.P. Malik, and G.S. Hope. "An Artificial Neural Network Based Adaptive Power System Stabilizer.” IEEE Transactions on Energy Conversion 8, no. 1 (March 1993): 71-77. doi:10.1109/60.207408.

[21] Hariri, A., and O.P. Malik. "A Fuzzy Logic Based Power System Stabilizer with Learning Ability.” IEEE Transactions on Energy Conversion 11, no. 4 (1996): 721-727. doi:10.1109/60.556370.

[22] Hosseinzadeh, N., and A. Kalam. “A Direct Adaptive Fuzzy Power System Stabilizer.” IEEE Transactions on Energy Conversion 14, no. 4 (1999): 1564-1571. doi:10.1109/60.815106.

[23] Dasu, Butti, Mangipudi Siva Kumar, and Rayapudi Srinivasa Rao. "Design of Robust Modified Power System Stabilizer for Dynamic Stability Improvement Using Particle Swarm Optimization Technique.” Ain Shams Engineering Journal 10, no. 4 (December 2019): 769-783. doi:10.1016/j.asej.2019.07.002.

[24] Ben Meziane, Khaddouj, and Ismail Boumhidi. "Optimized Type-2 Fuzzy Logic PSS Combined with $\mathrm{H}_{\infty}$ Tracking Control for the Multi-Machine Power System.” Advances in Intelligent Systems and Computing (2020): 193-204. doi:10.1007/978-981-150947-6_19.

[25] Devarapalli, Ramesh, and Biplab Bhattacharyya. "A Hybrid Modified Grey Wolf Optimization - sine Cosine Algorithm - based Power System Stabilizer Parameter Tuning in a Multimachine Power System.” Optimal Control Applications and Methods 41, no. 4 (March 26, 2020): 1143-1159. doi:10.1002/oca.2591. 
[26] Dey, Prasenjit, Anulekha Saha, Aniruddha Bhattacharya, and Boonruang Marungsri. "Analysis of the Effects of PSS and Renewable Integration to an Inter-Area Power Network to Improve Small Signal Stability.” Journal of Electrical Engineering \& Technology 15, no. 5 (August 3, 2020): 2057-2077. doi:10.1007/s42835-020-00499-2.

[27] Dey, Prasenjit, Aniruddha Bhattacharya, and Priyanath Das. "Tuned power system stabilizer for enhancing small signal stability of large interconnected power system." Caribbean Journal of Science 53, no. 1 (2019): 843-857.

[28] Nguyen Hien Trung, "Application of $\mathrm{RH}_{\infty}$ optimal theory to improve quality of Power system stabilizer." PhD thesis, Thai Nguyen University of Technology, Thai Nguyen University, (2012).

[29] IEEE Std. "IEEE Recommended Practice for Excitation System Models for Power System Stability studies." IEEE Standard 421.5-2005, IEEE Power Engineering Society by Energy Development and Power Generation Committee (2005).

[30] Youla, D., J. Bongiorno, and H. Jabr. "Modern Wiener--Hopf Design of Optimal Controllers Part I: The Single-Input-Output Case.” IEEE Transactions on Automatic Control 21, no. 1 (February 1976): 3-13. doi:10.1109/tac.1976.1101139.

[31] Ma, Jing, Shangxing Wang, Xiang Gao, Xiangsheng Zhu, Yang Qiu, and Zengping Wang. "Youla Parameterization Robust Control Strategy Considering Power System Uncertainties." Electric Power Components and Systems 42, no. 11 (July 30, 2014): 1152-1157. doi:10.1080/15325008.2014.921948.

[32] Gu, Da-Wei, Petko H. Petkov, and Mihail M Konstantinov. "Robust Control Design with MATLABß.” Advanced Textbooks in Control and Signal Processing (2013). doi:10.1007/978-1-4471-4682-7.

[33] Nguyen, Cong Huu, Kien Ngoc Vu, and Hai Trung Do. "Model Reduction Based on Triangle Realization with Pole Retention." Applied Mathematical Sciences 9 (2015): 2187-2196. doi:10.12988/ams.2015.5290.

[34] Moore, B. "Principal Component Analysis in Linear Systems: Controllability, Observability, and Model Reduction." IEEE Transactions on Automatic Control 26, no. 1 (February 1981): 17-32. doi:10.1109/tac.1981.1102568.

[35] Safonov, M.G., and R.Y. Chiang. "A Schur Method for Balanced-Truncation Model Reduction.” IEEE Transactions on Automatic Control 34, no. 7 (July 1989): 729-733. doi:10.1109/9.29399.

[36] Glover, Keith. "All Optimal Hankel-Norm Approximations of Linear Multivariable Systems and their L, $\infty$-Error Bounds $\dagger . "$ International Journal of Control 39, no. 6 (June 1984): 1115-1193. doi:10.1080/00207178408933239.

[37] A. Antoulas, Approximation of Large-Scale Dynamical System, SIAM: Philadelphia, PA, USA, (2005).

[38] Prajapati, Arvind Kumar, and Rajendra Prasad. "Order Reduction in Linear Dynamical Systems by Using Improved Balanced Realization Technique.” Circuits, Systems, and Signal Processing 38, no. 11 (April 5, 2019): 5289-5303. doi:10.1007/s00034019-01109-x.

[39] Zilouchian, A. "Balanced Structures and Model Reduction of Unstable Systems." IEEE Proceedings of the SOUTHEASTCON '91 (1991). doi:10.1109/secon.1991.147956.

[40] Minh, Ha Binh, Chu Binh Minh, and Victor Sreeram. "Balanced Generalized Singular Perturbation Method for Unstable Linear Time Invariant Continuous Systems.” Acta Mathematica Vietnamica 42, no. 4 (June 23, 2017): 615-635. doi:10.1007/s40306017-0215-2.

[41] Zhou, Kemin, Gregory Salomon, and Eva Wu. "Balanced realization and model reduction for unstable systems." International Journal of Robust and Nonlinear Control: IFAC - Affiliated Journal 9, no. 3 (1999): 183-198. doi:10.1002/(sici)10991239(199903)9:3<183::aid-rnc399>3.0.co;2-e.

[42] Jonckheere, E., and L. Silverman. “A New Set of Invariants for Linear Systems--Application to Reduced Order Compensator Design.” IEEE Transactions on Automatic Control 28, no. 10 (October 1983): 953-964. doi:10.1109/tac.1983.1103159. 


\section{Appendix I}

\section{Parameter and calculate the parameters of the model of exciter, AVR and, generator;}

Perunit $=1 ; \%$ parameters given in per unit of machine base

Frated $=50$;

Poles $=4$

Pfrated $=0.9$;

Vrated $=18 \mathrm{e} 3$;

Prated $=828315 \mathrm{e} 3$;

rs $=0$;

$\mathrm{xd}=1.790$

$\mathrm{xq}=1.660$

$\mathrm{xls}=0.215$

$\mathrm{xpd}=0.355$;

$\mathrm{xpq}=0.570$;

$\operatorname{xppd}=0.275$;

$\mathrm{xppq}=0.275$;

Tpdo $=7.9$

Tpqo $=0.410$

Tppdo $=0.032$;

Tppqo $=0.055$

$\mathrm{H}=3.77$;

Domega $=2 ; \%$ nonzero to account for damper winding not reprsented

$\mathrm{KA}=50$

$\mathrm{TA}=.06$

$\operatorname{VRmax}=1$

$\mathrm{VRmin}=-1$;

$\mathrm{TE}=0.052$;

$\mathrm{KE}=-0.0465$;

$\mathrm{TF}=1.0$;

$\mathrm{KF}=0.0832$

$\mathrm{AEx}=0.0012$

$\mathrm{BEx}=1.264$

$\%$ Calculate base quantities

we $=2 *$ pi $*$ Frated;

$w b=w e ;$

$w b m=w b *(2 /$ Poles $)$;

Sbase $=$ Prated/Pfrated;

$\%$ Use peak values of phase quantites for voltage and current

Vbase $=$ Vrated $*$ sqrt $(2 / 3)$;

Ibase $=\operatorname{sqrt}(2) *($ Sbase $/(\operatorname{sqrt}(3) *$ Vrated $))$;

Zbase $=$ Vbase $/$ Ibase;

re $=0 ; \%$ for real part of ac thevenin's source impedance

$\mathrm{xe}=0.1 ; \%$ for imag part of ac thevenin's source impedance

$\mathrm{Vi}=1.0+0 * \mathrm{j} ; \%$ for phasor voltage at infinite bus

$\mathrm{Si}=0.8+0.6^{*} \mathrm{j} ; \%$ for delivered complex power (lagging $\mathrm{Q}>0$ )

$\mathrm{Ie}=\operatorname{conj}(\mathrm{Si} / \mathrm{Vi})$;

$\mathrm{Eqe}=\mathrm{Vi}+((\mathrm{rs}+\mathrm{re})+(\mathrm{xq}+\mathrm{xe}) * \mathrm{j}) * \mathrm{Ie}$

$\mathrm{Vte}=\mathrm{Vi}+(\mathrm{re}+\mathrm{xe} * \mathrm{j}) * \mathrm{Ie}$

deltat $=$ angle $($ Vte $)$;

delta $=$ angle $($ Eqe $)$; 
Eqo $=\operatorname{abs}($ Eqe $)$

$\mathrm{I}=(\operatorname{conj}($ Eqe $) /$ Eqo $) * \mathrm{Ie} ; \% \mathrm{I}=\mathrm{Ie}^{*}(\cos ($ delta $)-\sin ($ delta $) * \mathrm{j})$;

$\mathrm{Iqo}=\operatorname{real}(\mathrm{I})$;

Ido $=-\operatorname{imag}(\mathrm{I})$

$\mathrm{Vio}=\operatorname{abs}(\mathrm{Vi})$;

$\mathrm{Vto}=(\operatorname{conj}($ Eqe $) /$ Eqo $) * \mathrm{Vte} ; \% \mathrm{Vto}=\mathrm{Vt} *(\cos ($ delta $)-\sin ($ delta $) * \mathrm{j})$;

$\mathrm{Vqo}=$ real $(\mathrm{Vto})$

$\mathrm{Vdo}=-\operatorname{imag}(\mathrm{Vto})$;

mag_Vto $=\operatorname{sqrt}(\mathrm{Vqo} * \mathrm{Vqo}+\mathrm{Vdo} * \mathrm{Vdo})$;

Sto $=$ Vto $* \operatorname{conj}(\mathrm{I})$;

Eqpo $=\mathrm{Vqo}+\mathrm{xpd}^{*} \mathrm{Ido}+\mathrm{rs} * \mathrm{Iqo} ;$

Edpo $=$ Vdo - xpq*Iqo + rs*Ido;

$\mathrm{Efo}=\mathrm{Eqo}+(\mathrm{xd}-\mathrm{xq}) * \mathrm{Ido}$

delio $=$ delta;

Pmecho $=\operatorname{real}($ Sto $) ; \%$ initialize excitation variables

$\mathrm{VR}=\mathrm{KE} * \mathrm{Efo}$

$\mathrm{Vs}=\mathrm{Efo} * \mathrm{KF} / \mathrm{TF}$;

Vref $=\mathrm{abs}($ Vto $)$;

$\mathrm{Dz}=(\mathrm{re}+\mathrm{rs}) *(\mathrm{re}+\mathrm{rs})+(\mathrm{xe}+\mathrm{xq}) *(\mathrm{xe}+\mathrm{xpd})$

$\%$ compute nonlinear gains in transfer functions

Vq_ratio $=$ Vqo/mag_Vto;

Vd_ratio $=$ Vdo/mag_Vto;

co $=\cos ($ delta $)$;

$\mathrm{si}=\sin ($ delta) ;

$\mathrm{K} 1=(\mathrm{Eqo} * \mathrm{Vio} / \mathrm{Dz}) *(\mathrm{re} * \mathrm{si}+(\mathrm{xe}+\mathrm{xpd}) * \mathrm{co})+(\mathrm{Iqo} * \mathrm{Vio} / \mathrm{Dz}) *((\mathrm{xq}-\mathrm{xpd}) *(\mathrm{xe}+\mathrm{xq}) * \mathrm{si}-\mathrm{re} *(\mathrm{xe}-\mathrm{xpd}) * \mathrm{co}) ;$

$\mathrm{K} 2=\mathrm{re} * \mathrm{Eqo} / \mathrm{Dz}+\mathrm{Iqo}^{*}(1+(\mathrm{xq}-\mathrm{xpd}) *(\mathrm{xe}+\mathrm{xq}) / \mathrm{Dz})$

$\mathrm{K} 3=1 /(1+(\mathrm{xd}-\mathrm{xpd}) *(\mathrm{xe}+\mathrm{xq}) / \mathrm{Dz})$

$\mathrm{K} 4=(\mathrm{Vio} *(\mathrm{xd}-\mathrm{xpd}) / \mathrm{Dz}) *((\mathrm{xe}+\mathrm{xq}) *$ si - re*co $)$;

$\mathrm{K} 5=\left(\mathrm{Vio} * \mathrm{Vq} \_\right.$ratio $\left.* x p d / \mathrm{Dz}\right) *(\mathrm{re} * \mathrm{co}-(\mathrm{xe}+\mathrm{xq}) * \mathrm{si})+\left(\mathrm{Vio} * \mathrm{Vd} \_\right.$ratio*xq/Dz $) *(\mathrm{re} * \mathrm{si}+(\mathrm{xe}+\mathrm{xpd}) * \mathrm{co})$;

$\mathrm{K} 6=\mathrm{Vq} \_$ratio $*(1-\mathrm{xpd} *(\mathrm{xe}+\mathrm{xq}) / \mathrm{Dz})+\mathrm{Vd} \_$ratio*xq*re/Dz;

Tdo_p=Tpdo;

Determine the transfer function of the model of exciter, AVR and, generator;

$\mathrm{M}=2 * \mathrm{H}$

$\mathrm{Ka}=\mathrm{KA}$;

$\mathrm{Ta}=\mathrm{TA}$;

$\mathrm{D}=$ Domega;

a1=[0 2*3.1416*50 0 0;-K1/M -D/M -K2/M 0;-K4/Tdo_p 0 -1/(Tdo_p*K3) 1/Tdo_p;-Ka*K5/Ta 0 -Ka*K6/Ta -1/Ta];

b1 $=[0 ; 0 ; 0 ;-\mathrm{Ka} / \mathrm{Ta}]$;

$\mathrm{c} 1=[0 ; 1 / \mathrm{M} ; 0 ; 0]$

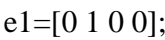

$\mathrm{d} 1=\left[\begin{array}{llll}1 & 0 & 0 & 0\end{array}\right]$

$\mathrm{s}=\mathrm{tf}(\mathrm{s}$ ');

$\mathrm{S} 22=\mathrm{e} 1 * \mathrm{inv}(\mathrm{s} * \mathrm{eye}(4,4)-\mathrm{a} 1) * \mathrm{~b} 1$;

$\mathrm{S} 21=\mathrm{e} 1 * \mathrm{inv}(\mathrm{s} * \mathrm{eye}(4,4)-\mathrm{a} 1) * \mathrm{c} 1$

$\mathrm{S} 12=\mathrm{d} 1 * \operatorname{inv}(\mathrm{s} *$ eye $(4,4)-\mathrm{a} 1) * \mathrm{~b} 1$;

$\mathrm{S} 11=\mathrm{d} 1 * \operatorname{inv}(\mathrm{s} *$ eye $(4,4)-\mathrm{a} 1) * \mathrm{c} 1$; 